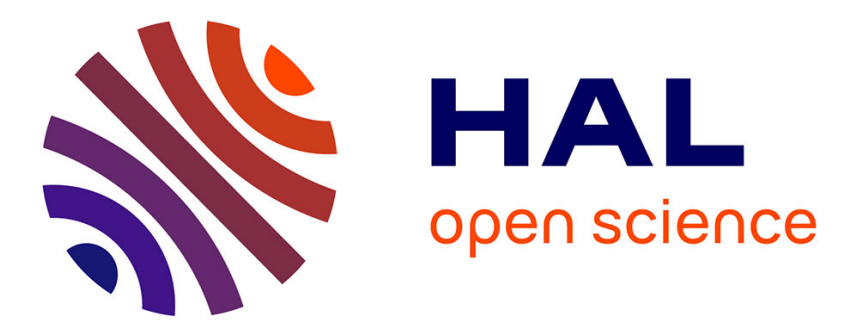

\title{
Innovative strategies for intervertebral disc regenerative medicine: From cell therapies to multiscale delivery systems
}

Nina Henry, Johann Clouet, Jean Le Bideau, Catherine Le Visage, Jérôme Guicheux

\section{To cite this version:}

Nina Henry, Johann Clouet, Jean Le Bideau, Catherine Le Visage, Jérôme Guicheux. Innovative strategies for intervertebral disc regenerative medicine: From cell therapies to multiscale delivery systems. Biotechnology Advances, 2018, 36 (1), pp.281 - 294. 10.1016/j.biotechadv.2017.11.009 . hal-01718005

\section{HAL Id: hal-01718005 \\ https://hal.science/hal-01718005}

Submitted on 3 Mar 2021

HAL is a multi-disciplinary open access archive for the deposit and dissemination of scientific research documents, whether they are published or not. The documents may come from teaching and research institutions in France or abroad, or from public or private research centers.
L'archive ouverte pluridisciplinaire HAL, est destinée au dépôt et à la diffusion de documents scientifiques de niveau recherche, publiés ou non, émanant des établissements d'enseignement et de recherche français ou étrangers, des laboratoires publics ou privés. 
Innovative strategies for intervertebral disc regenerative medicine: from cell therapies to multiscale delivery systems

Nina Henry ${ }^{\mathrm{a}, \mathrm{b}, \mathrm{c}}$, Johann Clouet ${ }^{\mathrm{a}, \mathrm{c}, \mathrm{d}, \mathrm{e}}$, Jean Le Bideau ${ }^{\mathrm{b}}$, Catherine Le Visage ${ }^{\mathrm{a}, \mathrm{c}^{*}}$, Jérôme Guicheux ${ }^{\mathrm{a}, \mathrm{c}, \mathrm{f}^{*}}$.

a. Inserm, UMR 1229, RMeS, Regenerative Medicine and Skeleton, Université de Nantes, ONIRIS, Nantes, France

b. Institut des Matériaux Jean Rouxel (IMN), Université de Nantes, CNRS, 2 rue de la Houssinière, BP 32229,44322 Nantes cedex 3, France

c. Université de Nantes, UFR Odontologie, Nantes, F-44042, France.

d. CHU Nantes, Pharmacie Centrale, PHU 11, Nantes, France.

e. Université de Nantes, UFR Sciences Biologiques et Pharmaceutiques, Nantes, France.

f. CHU Nantes, PHU 4 OTONN, Nantes, France.

* These authors equally contributed to this work.

Correspondence to:

C. Le Visage and J. Guicheux

INSERM U1229, 1 place Alexis Ricordeau, 44042 Nantes cedex 1, France.

Catherine.levisage@inserm.fr; jerome.guicheux@inserm.fr 


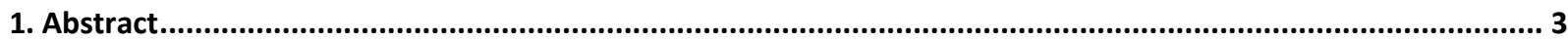

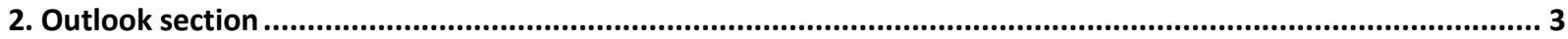

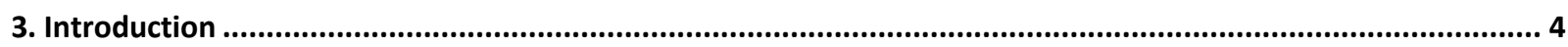

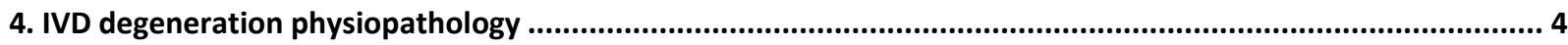

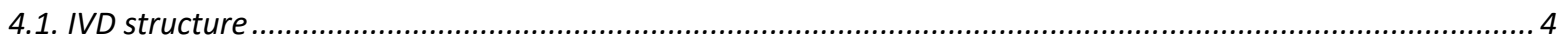

4.2. Extracellular matrix anabolism/catabolism homeostasis...................................................................... 5

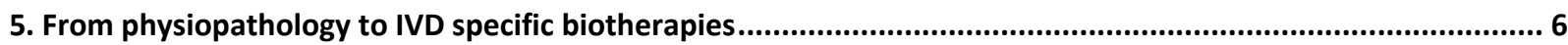

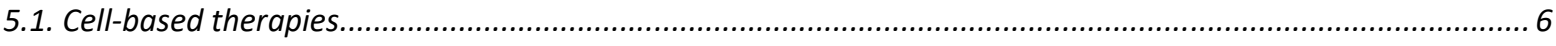

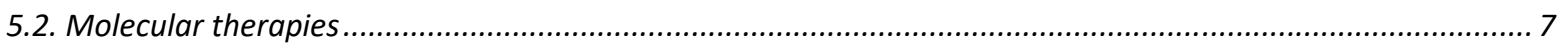

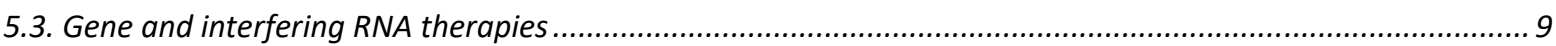

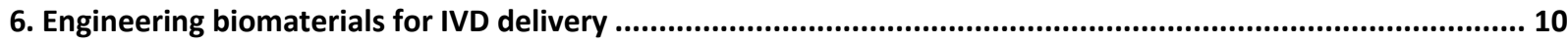

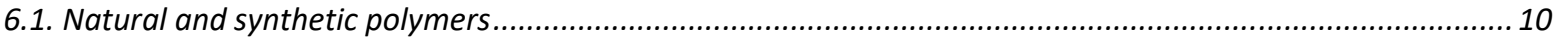

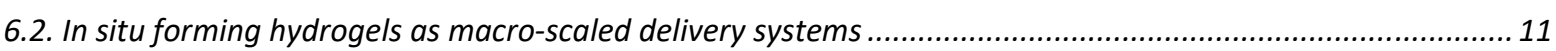

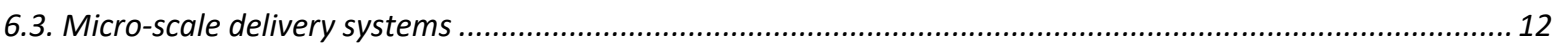

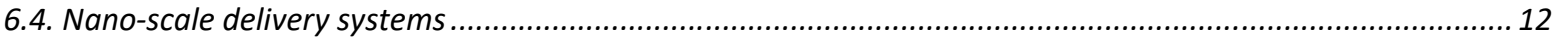

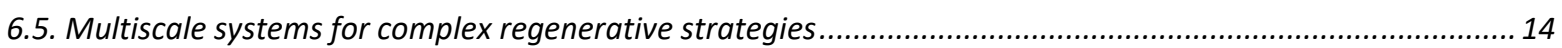

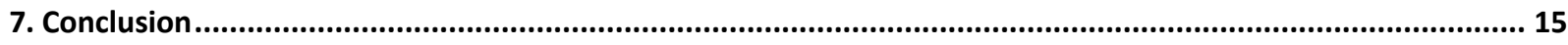

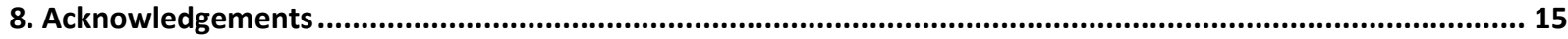

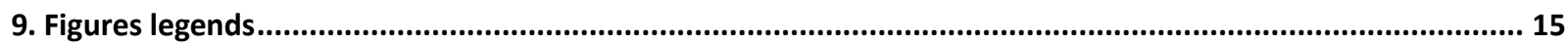

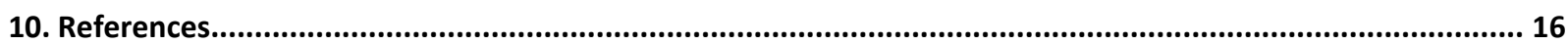




\section{Abstract}

2 As our understanding of the physiopathology of intervertebral disc (IVD) degeneration has improved, 3 novel therapeutic strategies have emerged, based on the local injection of cells, bioactive molecules, and 4 nucleic acids. However, with regard to the harsh environment constituted by degenerated IVDs, protecting 5 biologics from in situ degradation while allowing their long-term delivery is a major challenge. Yet, the 6 design of the optimal approach for IVD regeneration is still under debate and only a few papers provide a 7 critical assessment of IVD-specific carriers for local and sustained delivery of biologics. In this review, we 8 highlight the IVD-relevant polymers as well as their design as macro-, micro-, and nano-sized particles to 9 promote endogenous repair. Finally, we illustrate how multiscale systems, combining in situ-forming hydrogels with ready-to-use particles, might drive IVD regenerative medicine strategies towards 11 innovation.

\section{Outlook section}

- Intervertebral disc (IVD) regenerative medicine could benefit from the emergence of cell, molecule-, gene- and siRNA-based strategies.

- Design of IVD-specific carriers to protect biologics from in situ degradation, while allowing their local and sustained delivery, is a major challenge.

- A critical assessment of IVD-relevant natural and synthetic polymers, and their design as macro-, micro-, and nano-sized particles is provided.

- Multiscale systems, combining in situ forming hydrogels with ready-to-use particles, are introduced as new opportunities to stimulate IVD regeneration. 
Low back pain (LBP) is a common health condition and it is now well established that over $80 \%$ of adults will experience LBP during their lifetime. LBP has become the second most frequent cause of hospital visits and the leading cause of years lived with disability (Maher et al., 2017; Vos et al., 2016). Thanks to a better understanding of the etiology of LBP, the involvement of intervertebral disc (IVD) degeneration, referred to as disc degenerative disease (DDD) (Vos et al., 2016), was identified.

Current treatments of LBP include nonpharmacological, pharmacological, or surgical approaches, all aimed at controlling pain. For early degenerative stages, pharmacotherapies are mainly used (Abdel Shaheed et al., 2016) in association with rehabilitation or education of the patient (Latimer et al., 2004). For more advanced cases, surgical approaches are considered if conservative methods fail. Spine fusion aims to directly remove the IVD and immobilize the adjacent vertebrae. However, this intervention reduces spine mobility and neighboring segments can be affected by an accelerated degenerative process (Baliga et al., 2015). Arthroplasty, with Nucleus pulposus or IVD total replacement, aims at conserving the spine motion notably at the affected levels. These interventions, although generally clinically effective in alleviating pain (Galbusera et al., 2008), are very invasive and often include a long postoperative recovery and a non negligible risk of complications (Baliga et al., 2015).

Recent progress in our understanding of IVD physiopathology has led to new approaches for IVD regenerative medicine. In view of the decreasing number of cells in degenerating IVD, cell-based therapies were studied with growing interest. However, owing to the restrictive regulatory framework and the difficult clinical translatability of cell-based therapies, the use of biological factors targeting IVD degenerative processes was also contemplated. More recently, the role of gene mutations or microRNA dysregulation was identified at the onset of DDD, leading to the development of a third therapeutic approach based on the delivery of genes or small interfering RNAs (siRNA). In this context, this review will first briefly give recent insights into the pathophysiological mechanisms of DDD and then focus on describing cell-, molecule-, gene-, and siRNA-based strategies for tackling DDD as well as the scaffolding biomaterials used for their respective delivery.

\section{IVD degeneration physiopathology}

\subsection{IVD structure}

IVDs are fibro-cartilaginous tissues located between the vertebrae that are avascular and non-innervated (Whatley and Wen, 2012). They act as shock absorbers by distributing the mechanical loads along the spine and facilitate trunk mobility (Whatley and Wen, 2012; Zhou et al., 2014). IVDs are generally presented as a tripartite anatomical entity composed of the following parts (Figure 1).

The Nucleus pulposus (NP) is the inner part and the most hydrated region of the IVD (Fontana et al., 2015). NP cell density in human is the lowest of the IVD (Maroudas et al., 1975). These cells can be classified into two types: notochordal cells and nucleopulpocytes (Colombier et al., 2014). Human adult NP cells produce a highly hydrated extracellular matrix (ECM), rich in proteoglycans (mainly aggrecan) and type II collagen.

62 The Annulus fibrosus (AF) is the outer part of the IVD. It can be divided into the outer AF containing a oriented lamellar array of densely packed collagen fibers, while the inner AF is less dense and less organized (Raj, 2008; Whatley and Wen, 2012). AF cells have a fibroblastic morphology (Sakai and Grad, 2015). The AF is composed of water, types I and II collagen fibers, proteoglycans, and other proteins (Roughley, 2004). The AF retains the pressurized NP and allows for disc compression/decompression (Fontana et al., 2015). 
The endplates (EPs), composed of hyaline cartilage at the top and bottom of the vertebral bodies, interface the IVDs and the adjacent vertebrae. EPs cells are chondrocytes that synthesize an ECM rich in proteoglycans, types I and II collagens, and water. Mechanically, EPs support significant loads during daily-living activities and distribute the intradiscal pressures onto the adjacent vertebrae. They represent the main route for glucose and oxygen to reach the disc cells through the vertebral capillaries and for waste products to be eliminated from the disc (Fontana et al., 2015; Lotz et al., 2013).

\subsection{Extracellular matrix anabolism/catabolism homeostasis}

DDD has a complex and multifactorial etiology. Genetics, environmental causes, mechanical factors, aging, as well as systemic and toxic factors (Elmasry et al., 2015; Hadjipavlou et al., 2008) were identified as risk factors. Interestingly, recent data highlighted that the concomitant presence of notochordal cells and nucleopulpocytes was a pivotal factor for IVD ECM homeostasis (Erwin et al., 2006). Indeed, these two cell types interact via synthesized molecules and the early disappearance of notochordal cells is associated with a downregulation of nucleopulpocyte survival. This decrease in nucleopulpocyte density leads to a misbalance in the ECM anabolism/catabolism ratio that culminates in the alteration of the mechanical properties of IVDs (Erwin et al., 2011). In the advanced stages of IVD degeneration, proteoglycans, hydration, and the type-II/type-I collagen ratio are decreased(Russo et al., 2016; W.-J. Wang et al., 2015), leading to a dehydrated and fibrotic NP with a solid-like mechanical behavior (Russo et al., 2016). Additionally, the AF structure is disorganized and EPs calcify (Fontana et al., 2015; W.-J. Wang et al., 2015). As the degeneration worsens, innervation and vascularization of the disc occur (Whatley and Wen, 2012), leading to discogenic pain (Alkhatib et al., 2014).

From a molecular point of view, IVD degeneration is associated with an upregulation of pro-inflammatory cytokines such as interleukin-1 $\beta$ (IL-1 $\beta$ ) and tumor necrosis factor- $\alpha$ (TNF- $\alpha$ ) (Sakai and Grad, 2015). These two molecules trigger the over-expression of matrix metalloproteinases (MMPs) notably MMP-1, $2,-3,-7,-8$, and -13 . These MMPs are known for their proteolytic action toward collagen and proteoglycans (Kepler et al., 2013b; W.-J. Wang et al., 2015). Similarly to MMPs, there is a marked increase in the a disintegrin and metalloprotease with thrombospondin motifs (ADAMTS) 4 and 5. ADAMTS 4 and 5 act as aggrecanases, thereby contributing to worsening ECM degradation (Molinos et al., 2015; W.-J. Wang et al., 2015). As a pro-inflammatory cytokine, IL-1 $\beta$ up-regulates the expression of vascular endothelial growth factor (VEGF), nerve growth factor (NGF), and brain-derived neurotrophic factor (BDNF), thereby triggering the neo-vascularization and neo-innervation of IVD that ultimately result in inflammation and pain (Alkhatib et al., 2014; Whatley and Wen, 2012). Finally, in the presence of TNF- $\alpha$ or IL-1 $\beta$, NP cells tend to secrete chemo-attractant molecules including (C-C motif) ligand $5 /$ regulated on activation of normal T cells expressed and secreted (CCL5/RANTES) or chemokine (C-XC motif) ligand 6 (CXCL6) (Grad et al., 2016), thus increasing the migration of mesenchymal stem cells (MSCs) (Pattappa et al., 2014). This increased secretion of CCL5 was correlated with painful degenerated IVDs (Kepler et al., 2013a). In addition, stromal cell-derived factor-1 (SDF-1) was over-expressed in degenerated IVDs and involved in NP cell apoptosis (Z. Liu et al., 2016). Interestingly, SDF-1 also demonstrated a chemo-attracting effect toward MSC migration in an ex vivo IVD culture model (Pereira et al., 2014).

In contrast to these catabolic factors, anabolic factors stimulate the biological cascade involved in regenerative processes. Among them, Transforming Growth Factor- $\beta$ (TGF- $\beta$ ) is known to play a pivotal role in collagen and proteoglycan synthesis and in ECM homeostasis (S. Wang et al., 2015). TGF- $\beta$ is also one of the most potent inhibitors of TNF- $\alpha$-induced upregulation of MMPs as well as of aggrecan and type-II collagen degradation (Yang et al., 2015). In parallel, Bone Morphogenic Proteins (BMPs) are known to increase proteoglycan and type-II collagen synthesis as well as cell proliferation and differentiation (S. Wang et al., 2015). Among them, Growth and Differentiation Factor-5 (GDF-5 or BMP-14) plays a crucial role during musculoskeletal development and postnatal IVD maintenance (Feng 
et al., 2015). GDF-5 gene mutations notably lead to disc abnormalities in mice (Li et al., 2004). GDF-5 also upregulates the proliferation and secretory activities of NP and AF cells (Chujo et al., 2006) and modulates MMPs, IL-1 $\beta$, or TNF- $\alpha$ expression levels (Enochson et al., 2014; Gruber et al., 2014a). Altogether, these data highlight the pivotal role of GDF-5 in IVD matrix homeostasis.

The ECM homeostasis of IVDs and the consequences associated with a homeostasis rupture are illustrated in Figure 2.

\section{From physiopathology to IVD specific biotherapies}

Regarding the multifactorial nature of DDD, three main therapeutic strategies were considered in the past few years: cell-, molecular-, and nucleic acid-based therapies (Figure 3).

\subsection{Cell-based therapies}

A converging body of evidence suggested that IVD degeneration originates from the early disappearance of IVD resident cells. Supplementation of the IVD with regenerative cells thus naturally emerged as a strategy. Repopulating a degenerated IVD with healthy cells aims at either (i) restoring tissue homeostasis by transplanting cells able to secrete a functional ECM or (ii) tackling in situ inflammation by transplanting stem cells with immune-suppressive and anti-inflammatory properties. To achieve these ambitious and clinically relevant objectives, various cells sources were considered. Logically, NP cells harvested from surgically removed IVDs were the first to be used, with promising results in a canine study and in human clinical trials (Meisel et al., 2007). However, their further use was dramatically hampered by the low cell number harvested (Sakai and Grad, 2015). In parallel, pluripotent stem cells such as embryonic stem cells could be of great interest in view of their theoretical potential to differentiate into NP cells. Nevertheless, legal and ethical controversies limit the use of these cells for clinical application. Induced pluripotent stem (iPS) cells were also considered for various applications in regenerative medicine (Hirshi et al., 2014) and their suitability for IVD repair is being studied (Chen et al., 2013) but further studies are needed before their potential can be judged. Last but not least, adipose- (ASCs) or bone marrow-derived (MSCs) mesenchymal stem cells in their undifferentiated state are likely the most widely used in the DDD context. In addition to providing us with promising results (see next section), the extensive use of MSCs raised the question of their allogeneic or autologous origin (Richardson et al., 2016). Indeed, MSCs are considered hypo-immunogenic and immune-evasive cells able to be transplanted across major histocompatibility barriers (Ankrum et al., 2014), making the use of allogeneic MSCs a credible alternative to autologous ones.

ASCs are considered particularly advantageous because of their abundance in fat tissue, their accessibility, and their more potent immuno-modulatory effects in comparison with MSC isolated from bone marrow (Li et al., 2015). Of interest, human ASCs exhibit a nucleopulpogenic potential when committed with TGF- $\beta 1$ and GDF-5 (Colombier et al., 2016). When implanted in mice, these cells also demonstrated their ability to secrete GAGs and type II collagen, consistently with native NP cell capacities (Colombier et al., 2016). In rabbits, undifferentiated MSCs injected in the NP inhibited disc degeneration by reducing MMP2, MMP-3, and MMP-13 expression and by promoting type-II collagen synthesis, resulting in the maintenance of the IVD structure (Miyamoto et al., 2010). The beneficial outcomes of injecting undifferentiated MSCs were further demonstrated in other animal models, such as rat, mouse, dog, or pig models (Henriksson et al., 2009; Hiyama et al., 2008; Jeong et al., 2009; Marfia et al., 2014; Richardson et al., 2016). In these studies, IVD degeneration was significantly slowed down, disc height and MRI signal intensity improved, and nucleopulpogenic ECM neo-synthesis was observed. In humans, the intradiscal injection of MSCs could lower pain and disability (Orozco et al., 2011). This relief was associated with the anti-inflammatory (Maria et al., 2016; Sakai and Grad, 2015) and pro-anabolic properties of MSCs (Shabbir et al., 2009). Several ongoing clinical trials are conducted worldwide to determine the optimal cell source (autologous or allogeneic) to be used in DDD (Sakai and Andersson, 2015). 
Despite their global promise, the intradiscal injection of "naked" MSCs remains hampered by the harsh environmental condition the cells experience when injected into a degenerated IVD (low oxygen tension, low nutrient level, metabolic product accumulation, acidic $\mathrm{pH}$, high osmolarity, and high intradiscal pressure). These stringent conditions are responsible for the poor survival rate and altered activity of the injected cells. To overcome this hurdle, tissue engineers proposed to use cytoprotective 3D scaffolds able to create a biomimetic environment that could support cell survival. These scaffolds could additionally promote cell retention at the injection site thereby limiting the risk of off-target effects related to cell effusion. These scaffolds will be detailed in the last section of this review.

\subsection{Molecular therapies}

More recently, and facing the numerous limitations of cell transplantation, an alternative to cell-based therapies emerged. It consists in exploiting the ability of chemoattractant molecules to mobilize and recruit endogenous progenitor cells at the degenerated site (Illien-Jünger et al., 2012). This strategy, based on the capability of the endogenous body to self-regenerate, could free clinicians from the restrictive regulatory framework and cost ineffectiveness of cell transplantation. With respect to the myriad of factors playing a crucial role in IVD physiopathology, many chemoattractant, pro-anabolic, and anti-catabolic molecules were contemplated for the stimulation of resident cells or the attraction/recruitment of endogenous progenitors.

One key factor for improving the endogenous repair of IVDs via cell attraction/recruitment is the presence of endogenous progenitors with stem cell properties in the IVD (Risbud et al., 2007). These IVD-derived progenitor cells (either from NP or EPs) are very similar to MSCs isolated from the bone marrow of the same patient (Blanco et al., 2010). Interestingly, analyses of the migration capacity of progenitors located in the NP, AF, and EP indicate that EP progenitors have the highest migration and invasion potency (S. Liu et al., 2016). To favor cell migration in degenerative IVDs, chemokines were studied since, as chemotactic cytokines, they are involved in cell mobilization, attraction, and homing. Regarding IVDs, the three main chemokines expressed are SDF-1, CCL5, and CXCL16, both in healthy or degenerated IVDs. Interestingly, the expression of SDF-1 and CXCR4 was upregulated in degenerated IVDs, notably in MSCs isolated from the EPs (S. Liu et al., 2016; Zhang et al., 2014). SDF-1 also increased MSC attraction in a nucleotomized disc model (Pereira et al., 2014). The implication of SDF-1 in stem cell attraction was also demonstrated in many tissues including myocardium or periodontal ligament (Kaku et al., 2017; Purcell et al., 2012). Recently, IVD cells stimulated with IL-1 $\beta$ and TNF- $\alpha$ were found to secrete a higher concentration of CCL5 compared with IVD cells cultured under physiological conditions (Gruber et al., 2014b). The presence of CCL5 in degenerated IVDs as well as herniated and scoliotic discs was further demonstrated by proteomic assays in other in vitro studies in humans (Kawaguchi et al., 2002; Kepler et al., 2013a). Finally, in AF cells, CXCL16 is up-regulated by IL-1 $\beta$, suggesting a role for the CXCL16/CXCR6 system (Gruber et al., 2016).

Altogether, these data highlight the role of chemokines in the degenerative process of IVDs and strengthen their relevance in developing new strategies to attract progenitor cells and stimulate endogenous repair (Illien-Jünger et al., 2012).

In line with our understanding of DDD, anabolic factors can contribute to IVD regeneration. A large panel of anabolic factors was contemplated for IVD regeneration. Here, we mainly focus on the factors that demonstrated promising results in several reports.

TGF- $\beta$ contributes toward maintaining the expression levels of connective tissue growth factor (CCN2), one of the most potent factors able to stimulate aggrecan synthesis, in NP cells (Tran et al., 2014). In addition, CCN2 suppressed the inductive effect of IL-1 $\beta$ on catabolic genes (Tran et al., 2014). 
Considering that pro-inflammatory cytokines decreased CCN2 expression, this makes TGF- $\beta$ an anabolic factor able to counteract the effects of pro-inflammatory cytokines (Bedore et al., 2014). TGF- $\beta$ was also used in association with dexamethasone to stimulate the proliferation of degenerated human NP cells and exhibit an anti-catabolic gene expression profile (Liang et al., 2013).

GDF-5 is a major factor involved in early IVD development, and mutations of its related gene lead to severe structural impairment (Feng et al., 2015). Noteworthy, GDF-5 is down-regulated by IL-1 $\beta$ and TNF- $\alpha$. In vitro, GDF- 5 favors cell proliferation and stimulates the synthesis of proteoglycan and type II collagen, thus demonstrating its anabolic activity (Chujo et al., 2006). GDF-5 was used to differentiate human ASCs into nucleopulpocytes, in association with TGF- $\beta 1$ (Colombier et al., 2016). Interestingly, intradiscal injection of GDF-5 in rats and rabbits was shown to increase disc height. Consequently, clinical trials were conducted to evaluate the safety and efficacy of intradiscal injection of GDF-5 in patients with DDD (NCT01158924, NCT00813813, NCT01182337, and NCT01124006 on clinicaltrials.gov). As far as we know, no peer-reviewed publication is currently available. While a modest improvement in clinical parameters was observed, some adverse events were also reported suggesting that despite the relevance of GDF-5 in DDD, its direct intradiscal injection may not be the most suitable route.

Other anabolic factors were investigated and their anti-apoptotic activity toward NP cells was evidenced. Indeed, aside from promoting angiogenesis, it is now clear that in IVD, vascular endothelial growth factor (VEGF) also prevents NP cell apoptosis (Tran et al., 2010). Additionally, insulin-like growth factor (IGF1), platelet-derived growth factors (PDGFs), epidermal growth factor (EGF), and fibroblast growth factor (FGF-2) stimulate cell proliferation and inhibit cell apoptosis in human and animal cells (Vasiliadis and Pneumaticos, 2014). Together with the aforementioned CCN2 (Tran et al., 2014), these factors demonstrated their anabolic activity.

\section{Regarding the role of anabolic factors in DDD treatment, the use of platelet-rich plasma (PRP), which} contains a myriad of multifunctional growth factors, was recently proposed. Two clinical trials suggested the efficacy of PRP in DDD (Kristin et al., 2017; Tuakli-Wosornu et al., 2016). Further double-blind and controlled clinical trials are now required to confirm these first results.

Recent studies highlighted the key role of both TNF- $\alpha$ and interleukins in inflammation and further IVD degeneration, notably via the up regulation of MMPs and aggrecanases.

Thus, anti-TNF- $\alpha$ treatments (infliximab) were proposed and showed a significant decreased expression of IL-1 $\beta$ and IL-6 in NP cells (Walter et al., 2015), thereby demonstrating their anti-catabolic activity. In addition, the local administration of anti-IL-6 receptor, such as atlizumab or tocilizumab, lowered inflammation-related pain in humans (Sainoh et al., 2016). Interestingly, human IVD cells overexpressing IL-1 receptor antagonist were able to lower an IL-1-dependent increase of MMPs when injected into IVD degenerative explants, demonstrating their anti-catabolic potential (Le Maitre et al., 2007). In parallel, because NF- $\mathrm{KB}$ increases IVD degeneration via the upregulation of pro-inflammatory cytokines (Fontana et al., 2015), studies examined its inhibition. Indeed, human NP cell exposure to NF- $\mathrm{kB}$ inhibitor led to significantly decreased IL-1 $\beta$-dependent MMPs and ADAMTS upregulation (Orita et al., 2013; Zhongyi et al., 2015). In addition, inhibition of other cytokines such as BDNF, NGF, VEGF, or TNF- $\alpha$ was studied and showed promising results in the context of inflammation-associated DDD (Orita et al., 2011; Walter et al., 2015; Wu et al., 2011)

In parallel to the previously described IVD degenerative processes, aging-associated accumulation of oxidative damage is of great interest. Collagen is subject to glycoxidation reactions that form advancedglycation end-products (AGEs). The accumulation of these AGEs molecules contributes to IVD degeneration by increasing TNF- $\alpha$, MMPs, and aggrecanases expression, and to a greater extent AGEs participate in the alteration of structural and mechanical properties of the ECM (Colombini et al., 2008). Interestingly, administration of an anti-inflammatory drug (pentosan-polysulfate) associated with anti- 
AGE molecules (pyridoxamine) alleviated NP degeneration by lowering MMPs and ADAMTS production in diabetic mice (Illien-Junger et al., 2013).

With the discovery of molecules involved in IVD degenerative processes, new therapeutic approaches were proposed, either through stimulating anabolism or inhibiting catabolism. Despite encouraging results, the short half-life of such molecules does not allow for long-term activity, and they may not be sufficient to reactivate the physiological IVD machinery. Whether embedding these molecules in biomaterials to allow their in situ sustained and controlled delivery, while protecting them from proteolytic degradation, is a good option will be discussed in the next section.

\subsection{Gene and interfering RNA therapies}

An alternative to biotherapies may be the genetic modification of resident cells through gene transfer, for which two strategies can be envisioned: (i) The vector containing the gene can be introduced in the body (direct or in vivo gene therapy) or (ii) target cells can be harvested, genetically modified in vitro, and reimplanted (indirect or ex vivo gene therapy) (Goldspiel et al., 1993). Considering the decreased number of cells in degenerative IVD, direct gene therapy could be of interest for early degeneration, while the indirect approach seems more suitable for more severe cases. Two carriers were used for gene delivery: non-viral and viral vectors. Non-viral gene therapy refers to the use of naked DNA or cationic compounds (liposomes, polyplexes, lipopolyplexes) (Daraee et al., 2014; Rezaee et al., 2016). Such gene carriers help avoid the risks of mutagenicity, viral infections, and viral immunogenicity (Mintzer and Simanek, 2009). However, their application in IVD degeneration treatment remains limited. Regarding viral vectors, while retroviruses are the most commonly used, they have a more potent action on cells with a high dividing rate making them poorly adapted for NP-cell-mediated IVD gene therapy (Miller et al., 1990). Many authors thus chose adenoviruses despite their potential infectious and immunogenic risk owing to their higher transduction efficiency notably in quiescent or slowly dividing cells. Therapeutic genes encoding for antiinflammatory agents or MMPs inhibitors (e.g., TIMP-1) were considered as they could drastically reduce the expression of MMPs involved in ECM degradation (W.-J. Wang et al., 2015). It was found that the use of adenoviral vectors coding for BMP-2 and TIMP-1 on human degenerated disc cells increased proteoglycan synthesis (Wallach et al., 2003). Adenoviruses were also used to deliver genes coding for growth factors such as GDF-5 (X.-W. Luo et al., 2016) or TGF- $\beta$ (Nishida et al., 1999) and they were shown to efficiently stimulated anabolism.

In parallel to classic gene therapies, there is growing interest in the use of siRNAs. SiRNAs are short noncoding sequences of 20-25 nucleotides that control gene expression by binding to their target mRNA and causing the repression of RNA translation or degradation (Bartel, 2004). Many miRNAs deregulations emerged as key players in IVD degeneration by triggering NP cell apoptosis, ECM degradation, or NP cell proliferation and inflammatory response (see (Zhou et al., 2017) for review) and can thus be envisioned as new therapeutic targets.

Gene- and RNA interfering-based therapies seem to be particularly interesting for restoring the anabolic/catabolic balance in IVDs. However, as NP cell density drastically decreases during degeneration, the effectiveness of such approaches needs to be clarified. Finally, adenoviruses or siRNAs are not integrative tools and do not lead to extended gene expression. In addition, as siRNAs need to be protected from endonuclease degradation, the use of specifically designed biomaterial-based systems, as mentioned previously for peptidic molecules, could be a reasonable option.

As stated above, the broadening of our understanding of IVD degenerative processes led to new therapeutic strategies based on the local administration of cells, molecules, genes, or siRNA and several clinical trials assessing these three main therapeutic strategies have been reported (Table 1). As of 
November 2017, eight clinical trials have been published using autologous or allogenic cells, four trials have reported the injection of anabolic factor GDF-5 and only one trial is based on PRP. To the best of our knowledge, there is no ongoing clinical trial based on gene or RNA interfering therapies for IVD regeneration. Despite encouraging results, these therapies need further improvement with regard to the harsh environment in which these biologics are injected. Thus, biomaterials were considered so as to improve cell survival and protect molecules and nucleic acids from degradation. These biomaterials could additionally allow the biologics to be delivered in a spatiotemporally controlled manner thereby promoting long-term IVD regeneration.

\section{Engineering biomaterials for IVD delivery}

Successful delivery of fragile biologics into IVDs is highly challenging, mostly because of their short in vivo half-life. With the aim of targeting this poorly vascularized tissue, delivery routes are limited and thus minimally invasive direct injection received attention. While there are reviews extensively describing pharmaceutical innovations, including self-setting hydrogels, microspheres, and liposomes, for the oral (Diab et al., 2017), the intra-vitreal (Bochot and Fattal, 2012), and the transdermal (Naves et al., 2017) routes, only few papers are available providing a critical assessment of IVD-specific approaches for local and sustained delivery. Here, we highlight the rational selection of natural or synthetic polymers, we exemplify the design of delivery systems based on macro-, micro-, and nano- sized properties, and we illustrate how multiscale combined systems might help direct IVD regenerative medicine strategies.

\subsection{Natural and synthetic polymers}

One key parameter in the design of delivery systems is the selection of the constitutive polymer, since the chemical functionalities of a polymer affect all aspects of its performance, including encapsulation efficiency as well as polymer degradation rate and release (Mitragotri et al., 2014). As such, recent advances in delivery systems are based on polymers tailored for a specific tissue and engineered to exert distinct biological functions.

Among natural polymers, collagen, hyaluronic acid (HA), alginate, and chitosan were extensively studied (Sionkowska, 2011). Extracted from natural sources or obtained by bacterial fermentation, these macromolecules offer various advantages such as large-scale production, low toxicity, and similarity to ECM components.

Collagen, a major component of healthy IVD ECM, exhibits biodegradability, weak antigenicity, and superior biocompatibility compared with other natural proteins. The widespread biomedical use of collagen is based on its ability to be shaped into films, sponges, and micro- or nanoparticles (Liu et al., 2013). Gelatin, derived from collagen hydrolysis, is biodegradable in a physiological environment, with the formation of harmless metabolic products. In degenerated IVD, injectable gelatin microspheres impregnated with PRP reduced NP cells apoptosis and slowed down degeneration in adult rabbits (Sawamura et al., 2009). HA, another leading constituent of the NP ECM, was also studied as a scaffold for tissue engineering (Sionkowska et al., 2016), but less so for IVD strategies.

Although they cannot be found in the human body, alginate, a cell wall polysaccharide constituent of brown algae, and chitosan, a polysaccharide synthesized by crustaceans, were used for multiple biomedical applications (Bernkop-Schnürch and Dünnhaupt, 2012). Alginate microparticles were designed for the in vitro delivery of PRP in the treatment of degenerated IVDs (Sawamura et al., 2009); however, their ionic gelation-dependent low stability in the body might constitute a drawback. Similarly, cationic chitosan was considered for IVD regenerative applications, as a cell or molecule carrier (Cheng et al., 2010; Roughley et al., 2006). 
Synthetic polymers are obtained through reproducible industrial processes, with tunable physicochemical and mechanical properties. The most commonly used polymers for drug delivery systems are poly(lacticco-glycolic acid) (PLGA) and poly- $\varepsilon$-caprolactone (PCL) (Kondiah et al., 2016).

PLGA microspheres were widely used for the release of TGF- $\beta 3$ or anti-inflammatory molecules (Bhardwaj et al., 2007; Liang et al., 2013). They were used for recombinant human GDF-5 delivery in vivo in a rat model and increased the synthesis of aggrecan and type II collagen (Yan et al., 2013). PLGA microspheres were also used for the sustained delivery of IL- $1 \beta$ receptor antagonist in a 3D culture model, and this treatment effectively attenuated the IL-1 $\beta$-mediated inflammatory response of the $3 \mathrm{D}$ cultured NP cells (Gorth et al., 2012).

PCL, a semi-crystalline and hydrophobic polymer, is currently used in FDA-approved sutures for surgery and in commercially available contraceptive devices (Wei et al., 2009). PCL is often associated with hydrophilic polymers, either natural or synthetic ones (e.g., PEG, PAA or pNIPAAM), to form di- or triblock amphiphilic copolymers (Fu et al., 2014; Li and Tan, 2015). Moreover, PCL was extensively used for IVD tissue engineering, especially for AF repair (Wismer et al., 2014). PCL-based or PCL-coated microparticles were successfully designed for the sustained delivery of bioactive molecules, although not for IVD applications (Jung et al., 2015; Z. Luo et al., 2016).

In the context of IVD regenerative medicine, the usefulness of these natural and synthetic polymers is broadened further by our ability to create systems with multiple shapes and sizes that deliver drugs, cytokines, growth factors, or stem cells in a controlled manner. They are reviewed in the following sections.

\subsection{In situ forming hydrogels as macro-scaled delivery systems}

Hydrogels, networks of hydrophilic polymers capable of absorbing large amounts of water, are of particular interest for highly hydrated NP and AF tissue regeneration. Besides water, they provide mechanical support and a 3D microenvironment adapted for cell survival and proliferation. Attention was focused on the development of stimuli-responsive polymer solutions that could be injected in a minimally invasive manner prior to in situ solidifying, ensuring a perfect fit to the desired tissue. The in situ formation of hydrogels occurs through chemical covalent bonds or physical bonds (electrostatic or hydrophobic interactions).

Among chemical crosslinking, photo-induced crosslinking requires the production of radical initiating species and a precursor solution of a photoreactive polymer, usually a polyethylene glycol (PEG) acrylate or methacrylate derivative (Francisco et al., 2014; Li et al., 2014). While the use of photo-crosslinked polymers allows for time-controlled gelation, the limited access of the light apparatus to the target tissue weakens this strategy for IVD regeneration. Click chemistry, Schiff's base chemistry, Michael-type reactions, and enzymatic, protein, or $\mathrm{pH}$ modification-based crosslinking approaches might be better suited for IVD in situ gelation (Blanquer et al., 2014). These processes are generally compatible with cell or bioactive molecule loading as they often take place in mild conditions $\left(37^{\circ} \mathrm{C}\right.$, physiological $\mathrm{pH}$, short period). In the early $2000 \mathrm{~s}$, a silanized cellulose-based hydrogel, in which crosslinking is triggered by $\mathrm{pH}$, was developed (Bourges et al., 2002). The importance of this hydrogel has been demonstrated for the regeneration of articular cartilage (Vinatier et al., 2009) and myocardium (Mathieu et al., 2012) and it is currently studied for IVD regeneration (Henry et al., 2017).

Physically crosslinked hydrogels are formed via non-covalent interactions in response to an external stimulus ( $\mathrm{pH}$, temperature, molecule level, light, pressure, electric current) (Qiu and Park, 2012). Thermoresponsive polymers spontaneously undergo a sol-gel transition when exposed to physiological temperature after in vivo injection. Recombinant polypeptides [e.g., elastin-like polypeptide (Nettles et al., 2010)], naturally derived polysaccharides [e.g., chitosan (Cheng et al., 2013)], and synthetic polymers [e.g., block copolymers of PEG and PLGA (Tran et al., 2012), poly (N-isopropylacrylamide) (p- 
NIPAAM) (Willems et al., 2015)] are the most commonly reported thermo-responsive polymers for IVD regeneration.

419 In situ-forming hydrogels exhibit many advantages for IVD treatment. They provide an aqueous environment that can rehydrate the degenerated microenvironment, they protect biologics, and they can restore, at least partially, the mechanical properties of IVDs. The permeability of hydrogels facilitates good transport of nutrients to encapsulated cells. Nevertheless, hydrogels can present some restrictions due to, for example, their weak mechanical properties. One of the main drawbacks of in situ-forming bulk hydrogels is the difficulty to tune their release characteristics. Indeed, while the diffusion of entrapped molecules can be slightly modified by adjusting the polymer network mesh, exchanges with the targeted microenvironment are limited to the interface hydrogel/tissue, usually in the order of a few $\mathrm{cm}^{2} / \mathrm{g}$. By comparison, micro- and nano-scale delivery systems can develop areas greater than $1,000 \mathrm{~m}^{2} / \mathrm{g}$ as measured by $\mathrm{N}_{2}$ adsorption-desorption experiments.

\subsection{Micro-scale delivery systems}

In parallel to stimuli-responsive polymer solutions ensuring a perfect fit to the IVD defect following in situ gelation, injectable micro-sized particles, with diameters varying from $20 \mu \mathrm{m}$ to $200 \mu \mathrm{m}$, have release kinetics depending on their size and shape. Their release properties can be modified by tuning parameters such as the size, chemical composition, crosslinking degree, or molecular weight of the polymer (Balmert and Little, 2012). Moreover, chemical modification of the microparticle surface can allow for covalent coupling of factors such as antibodies and receptors. Microparticles are able to deliver biological factors over a long period while protecting them from inactivation (Wenk et al., 2009).

Many inorganic and polymer-based microparticles can be prepared by simple or double emulsion methods, in which a solution of the material is emulsified in water, followed by the formation of particles during the evaporation of the organic solvent. A recent modified protocol combines a crosslinking process and the emulsion step in an oil phase (Phromsopha and Baimark, 2014). Other production methods are spray drying, gelation, coacervation, electrospray, supercritical fluid mixing, and microfluidic technique. While their main advantage over classic emulsion is the narrower particle size distribution, the yield is often disappointing.

Recently, GDF-5-loaded PLGA microspheres, with an in vitro sustained delivery for 42 days, were injected into degenerated rat IVDs. Restoration of the disc height to almost $90 \%$ of the non-punctured disc was achieved (Yan et al., 2013). Moreover, the injection significantly increased aggrecan and type II collagen mRNA expression, whereas type I collagen mRNA expression was significantly decreased, suggesting that a micro-sized carrier could be of interest for IVD regeneration (Yan et al., 2013).

\subsection{Nano-scale delivery systems}

Alongside microparticles, many materials were used to design nanoparticles for biomedical applications, as nanocarriers are easily taken up by cells (Wilczewska et al., 2012). Polymeric nanoparticles, liposomes, dendrimers, polymers, silicon or carbon materials, and magnetic nanoparticles are examples of nanocarriers used as drug delivery systems notably for cancer (Sun et al., 2014) or bone regeneration (van Rijt and Habibovic, 2017). In this section, we highlight the particles that are feasible for use in the context of DDD.

Polymeric nanoparticles: Bioactive molecules can be either encapsulated or immobilized onto the surface of the nanoparticles, then released by desorption, diffusion, or nanoparticle erosion. Thus, degradable nanocarriers are widely used in biomedical applications as they can be hydrolyzed in situ (Kohane et al., 2006) and often considered to be biocompatible with tissues and cells, since they do not induce pro-inflammatory or immune reactions (des Rieux et al., 2006). An upregulation of aggrecan and type II collagen was achieved by using chitosan/Poly-(c-glutamic acid) nanoparticles loaded with the anti- 
inflammatory drug diclofenac. These nanoparticles were injected into a needle-punctured bovine IVD cultured in vitro with IL-1 $\beta$. Additionally, down-regulation of IL-6, IL-8, MMP1, and MMP3 was noted (Teixeira et al., 2016).

Self-organized spherical liposomes, usually $80-300 \mathrm{~nm}$ in diameter, contain at least one lipid bilayer surrounding an aqueous core (Daraee et al., 2014). They are thus able to encapsulate both hydrophobic and hydrophilic molecules within the lipid bilayer or the aqueous core, respectively. Liposomes were first used to improve the solubility and therapeutic index of chemotherapeutic agents, by allowing targeted delivery and enhanced tissue penetration. Since liposomes interact with cells by adsorption, fusion, endocytosis, or lipid transfer, they were studied as gene and siRNA carriers, especially cationic liposomes (Majzoub et al., 2016). The release kinetics can be tuned by the liposome composition, pH, osmotic gradient, incorporation of temperature- or $\mathrm{pH}$-sensitive lipids (dos Santos Giuberti et al., 2011), and the surrounding environment. Liposomes were thus used for drug delivery in various applications such as in anti-cancer or anti-inflammation therapies or to reach specific organs (lungs, liver, spleen, brain). However, to date, their use for tackling IVD degeneration has not been reported. Interestingly, lipid nanocapsules were successfully designed for nucleic acid delivery (Huynh et al., 2009) and their application in siRNA delivery for IVD regeneration could be of interest.

Dendrimers are branched polymers whose toxicity is mainly related to functional groups presented at the surface layer and can be lowered by functionalization, e.g., by PEGylation (Zeng et al., 2016). This functionalization improves the surface activity of dendrimers as well as their biological and physicochemical properties. Drugs are entrapped in the internal structure of the dendrimer, adsorbed or chemically bonded onto the dendrimer surface according to its properties (sensitivity to temperature or $\mathrm{pH}$, toxicity, solubility). One of the most commonly used in biomedical applications is poly-(amino amide; PAMAM-) as it was proven to be non-toxic and safe (Chauhan et al., 2009) and its capacity for gene or drug delivery was extensively explored (Zhao et al., 2011). Indeed, PAMAM dendrimers can modulate cytokine and chemokine release (Seelbach et al., 2015) and exhibit anti-inflammatory behavior by inhibiting proinflammatory cytokine secretion (Bosch, 2011). Thereby, dendrimers demonstrated their suitability in rheumatoid arthritis and musculoskeletal diseases and their application in IVD regeneration could be envisioned.

Carbon nanotubes are the most commonly used carbon nanoparticles and were widely studied for drug delivery in biomedical applications (Beg et al., 2011). They are characterized by a single or multiwall graphene-based tube with a high specific surface area and possibly excellent electronic and thermal conductivity (Beg et al., 2011). They have exceptional mechanical properties and are thus of interest as fillers in composite materials (Harrison and Atala, 2007). Toxicity due to their dimensions and released impurities was reported, but their biocompatibility can be enhanced with chemical surface engraftment of PEG, PAMAM, or albumin (Harrison and Atala, 2007). Molecules are encapsulated inside carbon nanotubes or chemically adsorbed onto their surface. Carbon nanotubes improve the mechanical properties of hydrogels (Dong et al., 2013) and can be of potential interest for IVD regenerative medicine.

Mesoporous silica nanoparticles are a widely studied biomaterial for their drug delivery capacity in particular for cancer therapies (Yang and Yu, 2016) or nerve growth (Sun et al., 2016). Indeed, mesoporous colloidal silica exhibit several advantages such as cytocompatibility, a high specific surface area, and ease of functionalization (Moritz and Geszke-Moritz, 2015). Additionally, the size, shape, surface pattern, porosity, and pore size of silica nanoparticles are easily tunable (Hoffmann et al., 2006). In the biomedical field, the best known mesoporous silica nanoparticles are MCM-41 and SBA-15. Drug loading into mesoporous silica might occur via chemical or physical adsorption, and release is usually controlled by diffusion throughout the mesopores. The potential of these particles was demonstrated for biomedical applications (Vallet-Regi and Balas, 2008) and more recently for the IVD (Henry et al., 2017). 


\subsection{Multiscale systems for complex regenerative strategies}

510 Over the past few years, composite materials, composed of at least two distinct components, drew attention in biomedical engineering since they possess additional properties that each constituent alone does not exhibit. They were widely studied for bone regeneration, and successful clinical trials were recently reviewed (Jahan and Tabrizian, 2016).

514 Regarding specific IVD applications, we would like to direct the reader's attention to the multiscale systems illustrated in Figure 4 that emphasize the integration of technologies such as in situ-forming hydrogels with ready-to-use micro- or nanoparticles. The assembly of specific functionalities obtained by combining a bulk matrix, to restore hydration and mechanical properties, with a long-term reservoir of cells or molecules, to provide biological cues, could constitute a breakthrough in IVD regenerative therapies. The main outcome of this review is to highlight the crucial role of biomaterials in IVD regenerative medicine strategies. With regard to the aforementioned device needs, we would like to stress that biomaterials are considered the driving force of the IVD regenerative medicine train (Figure 5).

Biomaterials are essential for the design and development of hydrogels capable of restoring load-bearing function while supporting cells until an appropriate ECM is synthesized. Biomaterials are also essential for engineering efficient and robust delivery devices that can be tailored to specific tissues.

For example, we recently reported on a multiscale system where an Si-HPMC hydrogel supplemented with rod-shaped silica nanofibers provided sustained release of TGF- $\beta 1$ and GDF- 5 , compared with the plain hydrogel, while maintaining their in vitro biological activity (Henry et al., 2017). Recently, TGF- $\beta 3$ loaded PLGA nanoparticles dispersed in a dextran/gelatin hydrogel, although not injectable, increased the gene expression of both aggrecan and type II collagen of MSCs in vitro (Gan et al., 2016). We believe that promising engineering technologies such as interpenetrating network-strengthened hydrogels (Gan et al., 2017), self-assembling nanofibrous peptide hydrogels (Wan et al., 2016), and programmed sequential bioactive factor delivery to target multiple repair steps (Bayer et al., 2017) could lead to significant advances in IVD regenerative strategies. Finally, an ambitious strategy would aim at delivering chemo-attractants from micro- or nanoparticles to attract progenitor cells toward a hydrogel-based microenvironment that would promote endogenous repair. 


\section{Conclusion}

540 IVD degeneration is a major health concern and today, thanks to recent discoveries, the physiopathology of this disease is better understood. Building on this deeper knowledge, various biotherapies were proposed in the past few years, including cell-based therapies, molecular therapies, and nucleic acid-based therapies. These therapies aim at locally injecting biologics including cells, proteins, or DNA as mentioned earlier. Even if promising results have been obtained in vitro, the harsh environment of degenerated IVDs is a major concern that has hampered the clinical translatability of such concepts. The main outcome of this review is to highlight the essential role of biomaterials in strategies for IVD regenerative medicine. Indeed, injectable in situ crosslinking hydrogels could restore IVD height and hydration and would be particularly suited for IVD regenerative strategies. Additionally, hydrogels can improve cell viability and protect bioactive molecules from in situ degradation. Finally, hydrogels can be used as scaffolds, supplemented or not with micro- or nanoparticles. These so-formed multiscale systems would allow for a sustained delivery of the biologics promoting long-term IVD regenerative processes.

The design of the optimal system for IVD regeneration is still under debate as disc degeneration is a multifactorial disease. Cell-based therapies were widely considered in view of the major decrease in cell numbers that is observed with degeneration. However, the regulatory framework and the costs associated with these strategies may restrict their use. We believe that an effective approach would target the early degenerative processes and involve multiscale biomaterials allowing molecules to be sustainably delivered in situ and enabling a prolonged stimulation of endogenous repair.

\section{Acknowledgements}

The authors acknowledge financial support from: Fondation de l'Avenir pour la Recherche Médicale Appliquée (AP-RMA-2015-018), Région Pays de la Loire (Paris Scientifique BIO2, LMA project and DIVA project), Agence Nationale pour la Recherche (REMEDIV, JC/JC STIMUDISC) and Fondation pour la Recherche Médicale (DBS20131128442).

\section{Figures legends}

Figure 1: Healthy intervertebral disc (IVD) local vascularization, innervation, and internal organization

A. Located between vertebrae, the IVD is composed of two vertebral endplates, an Annulus fibrosus (purple) and a Nucleus pulposus (NP, blue). Since the IVD is non-innervated and non-vascularized, oxygen and glucose supply as well as metabolite excretion occur by diffusion through the vertebral endplates. This particular property induces specific conditions of osmolarity and $\mathrm{pH}$, leading the IVD resident cells to adapt their metabolism. B. In AF tissue, fibroblast-like cells are organized parallel to collagen concentric lamellae. In NP tissue, large vacuolated notochordal cells and nucleopulpocytes coexist and ensure homeostasis of the extracellular matrix.

\section{Figure 2: NP homeostasis rupture leads to IVD degeneration}

In a healthy IVD, regulation of anabolic and catabolic processes (i.e., homeostasis) enables the tissue to be hydrated and maintains its mechanical properties. Under various factors such as genetics, aging, environmental causes, or mechanical stress, the cellular dialogue underlying the extracellular matrix homeostasis is disrupted. This rupture causes lower anabolism and increased catabolism, ultimately 
leading to ECM degradation, tissue inflammation, vascularization, fibrosis, and nerve ingrowth. Altogether, these phenomena are the key players in IVD degeneration.

\section{Figure 3: Current IVD regenerative medicine is based on three approaches}

Cell-based therapies. Considering the pivotal role of the decreased cell number in IVD degeneration, cell-based therapies have been increasingly considered. Autologous or allogeneic cells have been proposed and stem cells have been the subject of major investigations. Stem cells have been mainly isolated from adipose tissue or bone marrow and more recently pluripotent stem cells have been contemplated. It is also largely debated whether the optimal cells for IVD repair should be differentiated or undifferentiated. Molecular therapies. The broadened understanding of the phenomena involved during IVD degeneration has made it possible to consider molecular therapies via the direct injection of various factors to promote anabolism, to manage inflammation, or to attract regenerative cells. Nucleic acid-based therapies. Recent approaches target DNA and miRNA sequences and mostly aim to downplay catabolic factor expression. Finally, combined approaches such as genetically modified cells that could contribute to decreasing MMP local expression and activity could potentiate the efficacy of these therapies.

Figure 4: Multiscale systems associate in situ-forming scaffolds with ready-to-use particles

In the context of IVD regenerative medicine, we propose to combine in situ-forming systems with readyto-use micro- or nanoparticles, thereby forming multiscale systems. We hypothesize that injectable polymers that undergo local gel formation will restore IVD hydration and mechanical properties, while micro- or nano-sized carriers loaded with cells or molecules will provide supportive cues for regenerative processes.

\section{Figure 5: Biomaterials: the driving force of the IVD regenerative medicine train}

Biomaterials are essential for the design and development of delivery systems for IVD regenerative medicine. They can protect and deliver nucleic acids, bioactive molecules, or cells for a long period and may thus contribute to regenerating the degraded ECM of IVDs.

\section{0. $\underline{\text { References }}$}

Abdel Shaheed, C., Maher, C.G., Williams, K.A., Day, R., McLachlan, A.J., 2016. Efficacy, Tolerability, and Dose-Dependent Effects of Opioid Analgesics for Low Back Pain. JAMA Intern. Med. 176, 958.

Alkhatib, B., Rosenzweig, D.H., Krock, E., Roughley, P.J., Beckman, L., Steffen, T., Weber, M.H., Ouellet, J.A., Haglund, L., Scoliosis, M., 2014. Acute mechanicalt injury of the human intervertebral dics - Link to degeneration and pain. Eur. Cell. Mater. 28, 98-111.

Ankrum, J.A., Ong, J.F., Karp, J.M., 2014. Mesenchymal stem cells: immune evasive, not immune privileged. Nat Biotechnol 32, 252-260.

Baliga, S., Treon, K., Craig, N.J.A., 2015. Low back pain: Current surgical approaches. Asian Spine J. 9, 645-657.

Balmert, S.C., Little, S.R., 2012. Biomimetic Delivery with Micro- and Nanoparticles. Adv. 
Mater. 24, 3757-3778.

Bartel, D.P., 2004. MicroRNAs: Genomics, Biogenesis, Mechanism, and Function. Cell 116, 281-297.

Bayer, E.A., Jordan, J., Gottardi, R., Fedorchak, M., Kumta, P.N., Little, S., 2017. Programmed Platelet Derived Growth Factor- $\beta$ and Bone Morphogenetic Protein-2 Delivery from a Hybrid Calcium Phosphate/Alginate Scaffold. Tissue Eng. Part A Ahead of print.

Bedore, J., Leask, A., Séguin, C.A., 2014. Targeting the extracellular matrix: Matricellular proteins regulate cell-extracellular matrix communication within distinct niches of the intervertebral disc. Matrix Biol. 37, 124-130.

Beg, S., Rizwan, M., Sheikh, A.M., Hasnain, M.S., Anwer, K., Kohli, K., 2011. Advancement in carbon nanotubes: Basics, biomedical applications and toxicity. J. Pharm. Pharmacol. 63, 141-163.

Bernkop-Schnürch, A., Dünnhaupt, S., 2012. Chitosan-based drug delivery systems. Eur. J. Pharm. Biopharm. 81, 463-469.

Bhardwaj, U., Sura, R., Papadimitrakopoulos, F., Burgess, D.J., 2007. Controlling acute inflammation with fast releasing dexamethasone-PLGA microsphere/pva hydrogel composites for implantable devices. J. diabetes Sci. Technol. 1, 8-17.

Blanco, J.F., Graciani, I.F., Sanchez-Guijo, F.M., Muntion, S., Hernandez-Campo, P., Santamaria, C., Carrancio, S., Barbado, M.-V., Cruz, G., Gutierrez-Cosio, S., Herrero, C., San Miguel, J.F., Brinon, J.G., del Canizo, M.-C., 2010. Isolation and characterization of mesenchymal stromal cells from human degenerated nucleus pulposus: comparison with bone marrow mesenchymal stromal cells from the same subjects. Spine (Phila. Pa. 1976). $35,2259-2265$.

Blanquer, S.B.G., Grijpma, D.W., Poot, A. a., 2014. Delivery systems for the treatment of degenerated intervertebral discs. Adv. Drug Deliv. Rev. 84, 172-187.

Bochot, A., Fattal, E., 2012. Liposomes for intravitreal drug delivery: A state of the art. J. Control. Release 161, 628-634.

Bosch, X., 2011. Dendrimers to treat rheumatoid arthritis. ACS Nano 5, 6779-6785.

Bourges, X., Weiss, P., Daculsi, G., Legeay, G., 2002. Synthesis and general properties of silated-hydroxypropyl methylcellulose in prospect of biomedical use. Adv Colloid Interface Sci 99, 215-228.

Chauhan, A.S., Jain, N.K., Diwan, P. V., 2009. Pre-clinical and behavioural toxicity profile of PAMAM dendrimers in mice. Proc. R. Soc. A Math. Phys. Eng. Sci. 466, 1535-1550.

Chen, J., Lee, E.J., Jing, L., Christoforou, N., Leong, K.W., Setton, L.A., 2013. Differentiation of mouse induced pluripotent stem cells (iPSCs) into nucleus pulposus-like cells in vitro. PLoS One 8, e75548.

Cheng, Y.H., Yang, S.H., Liu, C.C., Gefen, A., Lin, F.H., 2013. Thermosensitive hydrogel made of ferulic acid-gelatin and chitosan glycerophosphate. Carbohydr. Polym. 92, 1512-1519.

Cheng, Y.H., Yang, S.H., Su, W.Y., Chen, Y.C., Yang, K.C., Cheng, W.T., Wu, S.C., Lin, F.H., 2010. Thermosensitive chitosan-gelatin-glycerol phosphate hydrogels as a cell carrier for nucleus pulposus regeneration: an in vitro study. Tissue Eng Part A 16, 695-703. 
664

665

666

667

668

669

670

671

672

673

674

675

676

677

678

679

680

681

682

683

684

685

686

687

688

689

690

691

692

693

694

695

696

697

698

699

700

701

702

703

704

705

Chujo, T., An, H.S., Akeda, K., 2006. Effects of Growth Differentiation Factor-5 on the Intervertebral Disc \%.. In Vitro Bovine Study and In Vivo Rabbit Disc Degeneration Model Study. Spine (Phila Pa 1976) 31, 2909-2917.

Colombier, P., Camus, A., Lescaudron, L., Clouet, J., Guicheux, J., 2014. Intervertebral disc regeneration: a great challenge for tissue engineers. Trends Biotechnol. 32, 433-5.

Colombier, P., Clouet, J., Boyer, C., Ruel, M., Bonin, G., Lesoeur, J., Moreau, A., Fellah, B.H., Weiss, P., Lescaudron, L., Camus, A., Guicheux, J., 2016. TGF- b 1 and GDF5 Act Synergistically to Drive the Differentiation of Human Adipose Stromal Cells toward Nucleus Pulposus -like Cells. Stem Cells 34, 653-667.

Colombini, A., Lombardi, G., Corsi, M.M., Banfi, G., 2008. Pathophysiology of the human intervertebral disc. Int. J. Biochem. Cell Biol. 40, 837-842.

Daraee, H., Etemadi, A., Kouhi, M., Alimirzalu, S., Akbarzadeh, A., 2014. Application of liposomes in medicine and drug delivery. Artif. Cells, Nanomedicine, Biotechnol. 1401, 111.

des Rieux, A., Fievez, V., Garinot, M., Schneider, Y.J., Préat, V., 2006. Nanoparticles as potential oral delivery systems of proteins and vaccines: A mechanistic approach. J. Control. Release 116, 1-27.

Diab, R., Canilho, N., Pavel, I.A., Haffner, F.B., Girardon, M., Pasc, A., 2017. Silica-based systems for oral delivery of drugs, macromolecules and cells. Adv. Colloid Interface Sci. In press.

Dong, W., Huang, C., Wang, Y., Sun, Y., Ma, P., Chen, M., 2013. Superior mechanical properties of double-network hydrogels reinforced by carbon nanotubes without organic modification. Int. J. Mol. Sci. 14, 22380-22394.

dos Santos Giuberti, C., de Oliveira Reis, E.C., Ribeiro Rocha, T.G., Leite, E.A., Lacerda, R.G., Ramaldes, G.A., de Oliveira, M.C., 2011. Study of the pilot production process of longcirculating and pH-sensitive liposomes containing cisplatin. J. Liposome Res. 21, 60-9.

Elmasry, S., Asfour, S., De Rivero Vaccari, J.P., Travascio, F., 2015. Effects of tobacco smoking on the degeneration of the intervertebral disc: A finite element study. PLoS One 10, 1-22.

Enochson, L., Stenberg, J., Brittberg, M., Lindahl, a, 2014. GDF5 reduces MMP13 expression in human chondrocytes via DKK1 mediated canonical Wnt signaling inhibition. Osteoarthritis Cartilage 22, 566-77.

Erwin, W.M., Ashman, K., O’Donnel, P., Inman, R.D., 2006. Nucleus pulposus notochord cells secrete connective tissue growth factor and up-regulate proteoglycan expression by intervertebral disc chondrocytes. Arthritis Rheum 54, 3859-3867.

Erwin, W.M., Islam, D., Inman, R.D., Fehlings, M.G., Tsui, F.W., 2011. Notochordal cells protect nucleus pulposus cells from degradation and apoptosis: implications for the mechanisms of intervertebral disc degeneration. Arthritis Res Ther 13, R215.

Feng, C., Liu, H., Yang, Y., Huang, B., Zhou, Y., 2015. Growth and Differentiation Factor-5 Contributes to the Structural and Functional Maintenance of the Intervertebral Disc. Cell. Physiol. Biochem. 35, 1-16.

Fontana, G., See, E., Pandit, A., 2015. Current trends in biologics delivery to restore intervertebral disc anabolism. Adv. Drug Deliv. Rev. 84, 146-158. 
Francisco, A.T., Hwang, P.Y., Jeong, C.G., Jing, L., Chen, J., Setton, L.A., 2014. Photocrosslinkable laminin-functionalized polyethylene glycol hydrogel for intervertebral disc regeneration. Acta Biomater. 10, 1102-1111.

Fu, W., Liu, Z., Feng, B., Hu, R., He, X., Wang, H, Meng, Y., Huang, H., Zhang, H., Wang, W., 2014. Electrospun gelatin / PCL and collagen / PLCL scaffolds for vascular tissue engineering. Int. J. Nanomedicine 9, 2335-2344.

Galbusera, F., Bellini, C.M., Zweig, T., Ferguson, S., Raimondi, M.T., Lamartina, C., BraydaBruno, M., Fornari, M., 2008. Design concepts in lumbar total disc arthroplasty. Eur. Spine J. 17, 1635-1650.

Gan, Y., Li, P., Wang, L., Mo, X., Song, L., Xu, Y., Zhao, C., Ouyang, B., Tu, B., Luo, L., Zhu, L., Dong, S., Li, F., Zhou, Q., 2017. An interpenetrating network-strengthened and toughened hydrogel that supports cell-based nucleus pulposus regeneration. Biomaterials $136,12-28$.

Gan, Y., Li, S., Li, P., Xu, Y., Wang, L., Zhao, C., Ouyang, B., Tu, B., Zhang, C., Luo, L., Luo, X., Mo, X., Zhou, Q., 2016. A Controlled Release Codelivery System of MSCs Encapsulated in Dextran/Gelatin Hydrogel with TGF- $\beta$ 3-Loaded Nanoparticles for Nucleus Pulposus Regeneration. Stem Cells Int. 2016.

Goldspiel, B.R., Green, L., Calis, K.A., 1993. Human gene therapy. Clin. Pharm. 12, 488-505.

Gorth, D.J., Mauck, R.L., Chiaro, J.A., Mohanraj, B., Hebela, N.M., Dodge, G.R., Elliott, D.M., Smith, L.J., 2012. IL-1 ra delivered from poly(lactic-co-glycolic acid) microspheres attenuates IL-1 $\beta$-mediated degradation of nucleus pulposus in vitro. Arthritis Res. Ther. 14, R179.

Grad, S., Bow, C., Karppinen, J., Luk, K.D., Cheung, K.M., Alini, M., Samartzis, D., 2016. Systemic blood plasma CCL5 and CXCL6: Potential biomarkers for human lumbar disc degeneration. Eur. Cell. Mater. 30, 1-10.

Gruber, H., Marrero, E., Ingram, J., Hoelscher, G., Hanley, E., 2016. The chemokine, CXCL16, and its receptor, CXCR6, are constitutively expressed in human annulus fibrosus and expression of CXCL16 is up-regulated by exposure to IL-1ß in vitro. Biotech. Histochem. 295, 1-8.

Gruber, H.E., Hoelscher, G.L., Ingram, J.A., Bethea, S., Hanley, E.N., 2014a. Growth and differentiation factor-5 (GDF-5) in the human intervertebral annulus cells and its modulation by IL-1b and TNF-b in vitro. Exp. Mol. Pathol. 96, 225-229.

Gruber, H.E., Hoelscher, G.L., Ingram, J.A., Bethea, S., Norton, H.J., Hanley, E.N., 2014b. Production and expression of RANTES (CCL5) by human disc cells and modulation by IL$1-\beta$ and TNF- $\alpha$ in 3D culture. Exp. Mol. Pathol. 96, 133-138.

Hadjipavlou, a G., Tzermiadianos, M.N., Bogduk, N., Zindrick, M.R., 2008. The pathophysiology of disc degeneration: a critical review. J. Bone Joint Surg. Br. 90, 12611270.

Harrison, B.S., Atala, A., 2007. Carbon nanotube applications for tissue engineering. Biomaterials 28, 344-353.

Henriksson, H.B., Svanvik, T., Jonsson, M., Sci, L.M., Hagman, M., Horn, M., Lindahl, A., Brisby, H., 2009. Transplantation of Human Mesenchymal Stems Cells Into Intervertebral 
Discs in a Xenogeneic Porcine Model. Spine (Phila. Pa. 1976). 34, 141-148.

Henry, N., Clouet, J., Le Visage, C., Weiss, P., Gautron, E., Humber, B., Terrisse, H., Guicheux, J., Le Bideau, J., 2017. Silica nanofibers as a new drug delivery system: a study of proteinsilica interactions. J Mater Chem B 5, 2908-2920.

Hirshi, K.K., Li, S., Roy, K., 2014. Induced pluripotent stem cells for regenerative medicine. Annu Rev Biomed Eng 16, 277-294.

Hiyama, A., Mochida, J., Iwashina, T., Omi, H., Watanabe, T., Serigano, K., Tamura, F., Sakai, D., 2008. Transplantation of mesenchymal stem cells in a canine disc degeneration model. J. Orthop. Res. 26, 589-600.

Hoffmann, F., Cornelius, M., Morell, J., Froba, M., 2006. Silica based mesoporous organicinorganic hybrid materials. Angew Chem Int Ed 45, 3216-51.

Huynh, N.T., Passirani, C., Saulnier, P., Benoit, J.P., 2009. Lipid nanocapsules: A new platform for nanomedicine. Int. J. Pharm. 379, 201-209.

Illien-Junger, S., Grosjean, F., Laudier, D.M., Vlassara, H., Striker, G.E., Iatridis, J.C., 2013. Combined Anti-Inflammatory and Anti-AGE Drug Treatments Have a Protective Effect on Intervertebral Discs in Mice with Diabetes. PLoS One 8.

Illien-Jünger, S., Pattappa, G., Peroglio, M., Benneker, L.M., Stoddart, M.J., Sakai, D., Mochida, J., Grad, S., Alini, M., 2012. Homing of Mesenchymal Stem Cells in Induced Degenerative Intervertebral Discs in a Whole Organ Culture System. Spine (Phila. Pa. 1976). 37, 18651873.

Jahan, K., Tabrizian, M., 2016. Composite biopolymers for bone regeneration enhancement in bony defects. Biomater. Sci. 4, 25-39.

Jeong, J.H., Jin, E.S., Min, J.K., Jeon, S.R., Park, C.S., Kim, H.S., Choi, K.H., 2009. Human mesenchymal stem cells implantation into the degenerated coccygeal disc of the rat. Cytotechnology 59, 55-64.

Jung, S.-M., Yoon, G.H., Lee, H.C., Shin, H.S., 2015. Chitosan nanoparticle/PCL nanofiber composite for wound dressing and drug delivery. J. Biomater. Sci. Polym. Ed. 26, 252-263.

Kaku, M., Kitami, M., Rosales Rocabado, J.M., Ida, T., Akiba, Y., Uoshima, K., 2017. Recruitment of bone marrow-derived cells to the periodontal ligament via the stromal cellderived factor-1/C-X-C chemokine receptor type 4 axis. J. Periodontal Res. Ahead of print.

Kawaguchi, S., Yamashita, T., Katahira, G., Yokozawa, H., Torigoe, T., Sato, N., 2002. Chemokine profile of herniated intervertebral discs infiltrated with monocytes and macrophages. Spine (Phila. Pa. 1976). 27, 1511-6.

Kepler, C.K., Markova, D.Z., Dibra, F., Yadla, S., Vaccaro, A.R., Risbud, M. V, Albert, T.J., Anderson, D.G., 2013a. Expression and relationship of proinflammatory chemokine RANTES/CCL5 and cytokine IL-1 $\beta$ in painful human intervertebral discs. Spine (Phila. Pa. 1976). 38, 873-80.

Kepler, C.K., Ponnappan, R.K., Tannoury, C. a, Risbud, M. V, Anderson, D.G., 2013b. The molecular basis of intervertebral disc degeneration. Spine J. 13, 318-30.

Kohane, D.S., Tse, J.Y., Yeo, Y., Padera, R., Shubina, M., Langer, R., 2006. Biodegradable polymeric microspheres and nanospheres for drug delivery in the peritoneum. J. Biomed. 
Mater. Res. - Part A 77, 351-361.

Kondiah, P.J., Choonara, Y.E., Kondiah, P.P.D., Marimuthu, T., Kumar, P., Du Toit, L.C., Pillay, V., 2016. A review of injectable polymeric hydrogel systems for application in bone tissue engineering. Molecules 21.

Kristin, C., Robert, S., Michelle, P., 2017. Effects of the intradiscal implantation of stromal vascular fraction plus platelet rich plasma in patients with degenerative disc disease. J. Transl. Med. 15, 12.

Latimer, J., Maher, C., Refshauge, K., 2004. The attitudes and beliefs of physiotherapy students to chronic back pain. Clin. J. Pain 20, 45-50.

Le Maitre, C.L., Hoyland, J.A., Freemont, A.J., 2007. Interleukin-1 receptor antagonist delivered directly and by gene therapy inhibits matrix degradation in the intact degenerate human intervertebral disc: an in situ zymographic and gene therapy study. Arthritis Res. Ther. 9, R83.

Li, C., Wang, T., Hu, L., Wei, Y., Liu, J., Mu, X., Nie, J., Yang, D., 2014. Photocrosslinkable bioadhesive based on dextran and PEG derivatives. Mater. Sci. Eng. C 35, 300-306.

Li, C., Wu, X., Tong, J., Yang, X., Zhao, J., Zheng, Q., Zhao, G., Ma, Z., 2015. Comparative analysis of human mesenchymal stem cells from bone marrow and adipose tissue under xeno-free conditions for cell therapy. Stem Cell Res. Ther. 6, 55.

Li, X., Leo, B.M., Beck, G., Balian, G., Anderson, G.D., 2004. Collagen and proteoglycan abnormalities in the GDF-5-deficient mice and molecular changes when treating disk cells with recombinant growth factor. Spine (Phila. Pa. 1976). 29, 2229-34.

Li, Z., Tan, B.H., 2015. Towards the development of polycaprolactone based amphiphilic block copolymers: Molecular design, self-assembly and biomedical applications. Mater. Sci. Eng. C 45, 620-634.

Liang, C.Z., Li, H., Tao, Y.Q., Peng, L.H., Gao, J.Q., Wu, J.J., Li, F.C., Hua, J.M., Chen, Q.X., 2013. Dual release of dexamethasone and TGF- $\beta 3$ from polymeric microspheres for stem cell matrix accumulation in a rat disc degeneration model. Acta Biomater. 9, 9423-9433.

Liu, S., Liang, H., Lee, S., Li, Z., Zhang, J., Fei, Q., 2016. Isolation and identification of stem cells from degenerated human intervertebral discs and their migration characteristics. Acta Biochim. Biophys. Sin. (Shanghai). 49, 101-109.

Liu, Y., Ren, L., Wang, Y., 2013. Crosslinked collagen-gelatin-hyaluronic acid biomimetic film for cornea tissue engineering applications. Mater. Sci. Eng. C 33, 196-201.

Liu, Z., Ma, C., Shen, J., Wang, D., Hao, J., Hu, Z., 2016. SDF-1/CXCR4 axis induces apoptosis of human degenerative nucleus pulposus cells via the NF- $\kappa$ B pathway. Mol. Med. Rep. 14, 783-789.

Lotz, J.C., Fields, A.J., Liebenberg, E.C., 2013. The role of the vertebral end plate in low back pain. Glob. spine J. 3, 153-64.

Luo, X.-W., Liu, K., Chen, Z., Zhao, M., Han, X.-W., Bai, Y.-G., Feng, G., 2016. Adenovirusmediated GDF-5 promotes the extracellular matrix expression in degenerative nucleus pulposus cells. J. Zhejiang Univ. Sci. B 17, 30-42. 
Luo, Z., Jin, L., Xu, L., Zhang, Z.L., Yu, J., Shi, S., Li, X., Chen, H., 2016. Thermosensitive PEG-PCL-PEG (PECE) hydrogel as an in situ gelling system for ocular drug delivery of diclofenac sodium. Drug Deliv. 23, 63-68.

Maher, C., Underwood, M., Buchbinder, R., 2017. Non-specific low back pain. Lancet 389, 73647.

Majzoub, R.N., Ewert, K.K., Safinya, C.R., 2016. Cationic liposome-nucleic acid nanoparticle assemblies with applications in gene delivery and gene silencing. Philos. Trans. A. Math. Phys. Eng. Sci. 374.

Marfia, G., Campanella, R., Navone, S.E., Zucca, I., Scotti, A., Figini, M., Di Vito, C., Alessandri, G., Riboni, L., Parati, E., 2014. Potential use of human adipose mesenchymal stromal cells for intervertebral disc regeneration: a preliminary study on biglycan-deficient murine model of chronic disc degeneration. Arthritis Res. Ther. 16, 457.

Maria, A.T.J., Toupet, K., Maumus, M., Fonteneau, G., Le Quellec, A., Jorgensen, C., Guilpain, P., Noël, D., 2016. Human adipose mesenchymal stem cells as potent anti-fibrosis therapy for systemic sclerosis. J. Autoimmun. 70, 1-9.

Maroudas, A., Stockwell, R.A., Nachemson, A., Urban, J., 1975. Factors involved in the nutrition of the human lumbar intervertebral disc: cellularity and diffusion of glucose in vitro. J. Anat. $120,113-30$.

Mathieu, E., Lamirault, G., Toquet, C., Lhommet, P., Rederstorff, E., Sourice, S., Biteau, K., Hulin, P., Forest, V., Weiss, P., Guicheux, J., Lemarchand, P., 2012. Intramyocardial Delivery of Mesenchymal Stem Cell-Seeded Hydrogel Preserves Cardiac Function and Attenuates Ventricular Remodeling after Myocardial Infarction. PLoS One 7, e51991.

Meisel, H.J., Siodla, V., Ganey, T., Minkus, Y., Hutton, W.C., Alasevic, O.J., 2007. Clinical experience in cell-based therapeutics: Disc chondrocyte transplantation. A treatment for degenerated or damaged intervertebral disc. Biomol. Eng. 24, 5-21.

Miller, D.G., Adam, M.A., Miller, A.D., 1990. Gene transfer by retrovirus vectors occurs only in cells that are actively replicating at the time of infection. Mol. Cell. Biol. 10, 4239-42.

Mintzer, M.A., Simanek, E.E., 2009. Nonviral vectors for gene delivery. Chem. Rev. 109, 259302.

Mitragotri, S., Burke, P. a., Langer, R., 2014. Overcoming the challenges in administering biopharmaceuticals: formulation and delivery strategies. Nat. Rev. Drug Discov. 13, 655672.

Miyamoto, T., Muneta, T., Tabuchi, T., Matsumoto, K., Saito, H., Tsuji, K., Sekiya, I., 2010. Intradiscal transplantation of synovial mesenchymal stem cells prevents intervertebral disc degeneration through suppression of matrix metalloproteinase-related genes in nucleus pulposus cells in rabbits. Arthritis Res. Ther. 12, R206.

Molinos, M., Almeida, C.R., Caldeira, J., Cunha, C., Goncalves, R.M., Barbosa, M.A., 2015. Inflammation in intervertebral disc degeneration and regeneration. J R Soc Interface 12, 20141191.

Moritz, M., Geszke-Moritz, M., 2015. Mesoporous materials as multifunctional tools in biosciences: Principles and applications. Mater. Sci. Eng. C 49, 114-151.

Naves, L., Dhand, C., Almeida, L., Rajamani, L., Ramakrishna, S., Soares, G., 2017. Poly(lactic- 
co-glycolic) acid drug delivery systems through transdermal pathway: an overview. Prog. Biomater. 6, 1-11.

Nettles, D.L., Chilkoti, A., Setton, L.A., 2010. Applications of Elastin-like Polypeptides in Tissue Engineering. Adv. Drug Deliv. Rev. 62, 1479-1485.

Nishida, K., Kang, J.D., Gilbertson, L.G., Moon, S., Suh, J., Vogt, M.T., Robbins, P.D., Evans, C.H., 1999. Modulation of the biologic activity of the rabbit intervertebral disc by gene therapy: An in vivo study of adenovirus-mediated transfer of the human transforming growth factor beta 1 encoding gene. Spine (Phila. Pa. 1976). 24, 2419-2425.

Orita, S., Eguchi, Y., Kamoda, H., Arai, G., Ishikawa, T., Miyagi, M., Inoue, G., Suzuki, M., Toyone, T., Aoki, Y., Takahashi, K., Ohtori, S., 2011. Brain-Derived Neurotrophic Factor Inhibition at the Punctured Intervertebral Disc Downregulates the Production of Calcitonin Gene-Related Peptide in Dorsal Root Ganglia in Rats. Spine (Phila. Pa. 1976). 36, $1737-$ 1743.

Orita, S., Miyagi, M., Kobori, S., Gemba, T., Ishikawa, T., Inoue, G., Toyone, T., Aoki, Y., Eguchi, Y., Takahashi, K., Ohtori, S., 2013. IkB kinase b inhibitor downregulates painrelated neuropeptide production in the sensory neurons innervating injured lumbar intervertebral discs in the dorsal root ganglia of rats. Spine J. 13, 284-288.

Orozco, L., Soler, R., Morera, C., Alberca, M., Sanchez, A., Garcia-Sancho, J., 2011. Intervertebral disc repair by autologous mesenchymal bone marrow cells: a pilot study. Transplantation 92, 822-828.

Pattappa, G., Peroglio, M., Sakai, D., Mochida, J., Benneker, L.M., Alini, M., Grad, S., Science, S., 2014. Ccl5 / Rantes Is a Key Chemoattractant Released By Degenerative Intervertebral Discs in Organ Culture. Eur Cell Mater 1, 124-136.

Pereira, C.L., Gonçalves, R.M., Peroglio, M., Pattappa, G., D’Este, M., Eglin, D., Barbosa, M. a, Alini, M., Grad, S., 2014. The effect of hyaluronan-based delivery of stromal cell-derived factor- 1 on the recruitment of MSCs in degenerating intervertebral discs. Biomaterials 35 , 8144-53.

Phromsopha, T., Baimark, Y., 2014. Preparation of starch/gelatin blend microparticles by a water-in-oil emulsion method for controlled release drug delivery. Int. J. Biomater. 2014, 16.

Purcell, B.P., Elser, J.A., Mu, A., Margulies, K.B., Burdick, J.A., 2012. Synergistic effects of SDF-1a chemokine and hyaluronic acid release from degradable hydrogels on directing bone marrow derived cell homing to the myocardium. Biomaterials 33, 7849-7857.

Qiu, Y., Park, K., 2012. Environment-sensitive hydrogels for drug delivery. Adv. Drug Deliv. Rev. 64, 49-60.

Raj, P.P., 2008. Intervertebral disc: Anatomy-physiology-pathophysiology-treatment. Pain Pract. $8,18-44$.

Rezaee, M., Oskuee, R.K., Nassirli, H., Malaekeh-Nikouei, B., 2016. Progress in the development of lipopolyplexes as efficient non-viral gene delivery systems. J. Control. Release 236, 1-14.

Richardson, S.M., Kalamegam, G., Pushparaj, P.N., Matta, C., Memic, A., Khademhosseini, A., Mobasheri, R., Poletti, F.L., Hoyland, J.A., Mobasheri, A., 2016. Mesenchymal stem cells in 
regenerative medicine: Focus on articular cartilage and intervertebral disc regeneration. Methods 99, 69-80.

Risbud, M. V, Guttapalli, A., Tsai, T.-T., Lee, J.Y., Danielson, K.G., Vaccaro, A.R., Albert, T.J., Gazit, Z., Gazit, D., Shapiro, I.M., 2007. Evidence for skeletal progenitor cells in the degenerate human intervertebral disc. Spine (Phila. Pa. 1976). 32, 2537-2544. doi:10.1097/BRS.0b013e318158dea6

Roughley, P., Hoemann, C., DesRosiers, E., Mwale, F., Antoniou, J., Alini, M., 2006. The potential of chitosan-based gels containing intervertebral disc cells for nucleus pulposus supplementation. Biomaterials 27, 388-396.

Roughley, P.J., 2004. Biology of intervertebral disc aging and degeneration: involvement of the extracellular matrix. Spine (Phila. Pa. 1976). 29, 2691-2699.

Russo, F., Hartman, R.A., Bell, K.M., Vo, N., Sowa, G.A., Kang, J.D., Vadala, G., Denaro, V., 2016. Biomechanical Evaluation of Transpedicular Nucleotomy with Intact Annulus Fibrosus. Spine (Phila Pa 1976) 42, E193-E201.

Sainoh, T., Orita, S., Miyagi, M., Inoue, G., Yamauchi, K., Suzuki, M., Sakuma, Y., Kubota, G., Oikawa, Y., Inage, K., Sato, J., Nakata, Y., Aoki, Y., Takahashi, K., Ohtori, S., 2016. Single intradiscal injection of the interleukin- 6 receptor antibody tocilizumab provides short-term relief of discogenic low back pain; prospective comparative cohort study. J. Orthop. Sci. 21, $2-6$.

Sakai, D., Andersson, G.B.J., 2015. Stem cell therapy for intervertebral disc regeneration: obstacles and solutions. Nat. Rev. Rheumatol. 11, 243-256. doi:10.1038/nrrheum.2015.13

Sakai, D., Grad, S., 2015. Advancing the cellular and molecular therapy for intervertebral disc disease. Adv. Drug Deliv. Rev. 84, 159-171.

Sawamura, K., Ikeda, T., Nagae, M., Okamoto, S., Mikami, Y., Hase, H., Ikoma, K., Yamada, T., Sakamoto, H., Matsuda, K., Tabata, Y., Kawata, M., Kubo, T., 2009. Characterization of in vivo effects of platelet-rich plasma and biodegradable gelatin hydrogel microspheres on degenerated intervertebral discs. Tissue Eng. Part A 15, 3719-3727.

Seelbach, R.J., Fransen, P., Pulido, D., D’Este, M., Duttenhoefer, F., Sauerbier, S., Freiman, T.M., Niemeyer, P., Albericio, F., Alini, M., Royo, M., Mata, A., Eglin, D., 2015. Injectable Hyaluronan Hydrogels with Peptide-Binding Dendrimers Modulate the Controlled Release of BMP-2 and TGF-b1. Macromol. Biosci. 15, 1035-1044.

Shabbir, A., Zisa, D., Suzuki, G., Lee, T., 2009. Heart failure therapy mediated by the trophic activities of bone marrow mesenchymal stem cells: a noninvasive therapeutic regimen. AJP Hear. Circ. Physiol. 296, H1888-H1897.

Sionkowska, A., 2011. Current research on the blends of natural and synthetic polymers as new biomaterials: Review. Prog. Polym. Sci. 36, 1254-1276.

Sionkowska, A., Kaczmarek, B., Lewandowska, K., Grabska, S., Pokrywczyńska, M., Kloskowski, T., Drewa, T., 2016. 3D composites based on the blends of chitosan and collagen with the addition of hyaluronic acid. Int. J. Biol. Macromol. 89, 442-448.

Sun, B., Taing, A., Liu, H., Nie, G., Wang, J., Fang, Y., Liu, L., Xue, Y., Shi, J., Liao, Y.-P., Ku, J., Xia, T., Liu, Y., 2016. Nerve Growth Factor-Conjugated Mesoporous Silica Nanoparticles Promote Neuron-Like PC12 Cell Proliferation and Neurite Growth. J. 
Nanosci. Nanotechnol. 16, 2390-3.

Sun, T., Zhang, Y.S., Pang, B., Hyun, D.C., Yang, M., Xia, Y., 2014. Engineered nanoparticles for drug delivery in cancer therapy. Angew. Chemie - Int. Ed. 53, 12320-12364.

Teixeira, G.Q., Leite Pereira, C., Castro, F., Ferreira, J.R., Gomez-Lazaro, M., Aguiar, P., Barbosa, M.A., Neidlinger-Wilke, C., Goncalves, R.M., 2016. Anti-inflammatory Chitosan/Poly-gamma-glutamic acid nanoparticles control inflammation while remodeling extracellular matrix in degenerated intervertebral disc. Acta Biomater. 42, 168-179.

Tran, C.M., Markova, D., Smith, H.E., Susarla, B., Ponnappan, R.K., Anderson, D.G., Symes, A., Shapiro, I.M., Risbud, M. V., 2010. Regulation of CCN2/connective tissue growth factor expression in the nucleus pulposus of the intervertebral disc: Role of smad and activator protein 1 signaling. Arthritis Rheum. 62, 1983-1992.

Tran, C.M., Schoepflin, Z.R., Markova, D.Z., Kepler, C.K., Anderson, D.G., Shapiro, I.M., Risbud, M. V, 2014. CCN2 Suppresses Catabolic Effects of Interleukin- $1 \beta$ through $\alpha 5 \beta 1$ and $\alpha$ V $\beta 3$ Integrins in Nucleus Pulposus Cells. J. Biol. Chem. 289, 7374-7387.

Tran, V.T., Karam, J.P., Garric, X., Coudane, J., Benoit, J.P., Montero-Menei, C.N., VenierJulienne, M.C., 2012. Protein-loaded PLGA-PEG-PLGA microspheres: a tool for cell therapy. Eur J Pharm Sci 45, 128-137.

Tuakli-Wosornu, Y.A., Terry, A., Boachie-Adjei, K., Harrison, J.R., Gribbin, C.K., LaSalle, E.E., Nguyen, J.T., Solomon, J.L., Lutz, G.E., 2016. Lumbar Intradiskal Platelet-Rich Plasma (PRP) Injections: A Prospective, Double-Blind, Randomized Controlled Study. PM R 8, 110 .

Vallet-Regi, M., Balas, F., 2008. Silica materials for medical applications. Open Biomed Eng J 2, $1-9$.

van Rijt, S., Habibovic, P., 2017. Enhancing regenerative approaches with nanoparticles. J. R. Soc. Interface 14.

Vasiliadis, E., Pneumaticos, S., 2014. Biologic treatment of mild and moderate intervertebral disc degeneration. Mol. Med. 20, 1.

Vinatier, C., Gauthier, O., Fatimi, A., Merceron, C., Masson, M., Moreau, A., Moreau, F., Fellah, B., Weiss, P., Guicheux, J., 2009. An injectable cellulose-based hydrogel for the transfer of autologous nasal chondrocytes in articular cartilage defects. Biotechnol. Bioeng. 102, 12591267.

Vos, T., Allen, C., Arora, M., Barber, R.M., Bhutta, Z.A., Brown, A., Carter, A., Casey, D.C., Charlson, F.J., Chen, A.Z., Coggeshall, M., Cornaby, L., Dandona, L., Dicker, D.J., Dilegge, T., Erskine, H.E., Ferrari, A.J., Fitzmaurice, C., Fleming, T., Forouzanfar, M.H., Fullman, N., Gething, P.W., Goldberg, E.M., Graetz, N., Haagsma, J.A., Hay, S.I., Johnson, C.O., Kassebaum, N.J., Kawashima, T., Kemmer, L., Khalil, I.A., Kinfu, Y., Kyu, H.H., Leung, J., Liang, X., Lim, S.S., Lopez, A.D., Lozano, R., Marczak, L., Mensah, G.A., Mokdad, A.H., Naghavi, M., Nguyen, G., Nsoesie, E., Olsen, H., Pigott, D.M., Pinho, C., Rankin, Z., Reinig, N., Salomon, J.A., Sandar, L., Smith, A., Stanaway, J., Steiner, C., Teeple, S., Thomas, B.A., Troeger, C., Wagner, J.A., Wang, H., Wanga, V., Whiteford, H.A., Zoeckler, L., Abajobir, A.A., Abate, K.H., Abbafati, C., Abbas, K.M., Abd-Allah, F., Abraham, B., Abubakar, I., Abu-Raddad, L.J., Abu-Rmeileh, N.M.E., Ackerman, I.N., Adebiyi, A.O., Ademi, Z., Adou, A.K., Afanvi, K.A., Agardh, E.E., Agarwal, A., Kiadaliri, A.A., 
Ahmadieh, H., Ajala, O.N., Akinyemi, R.O., Akseer, N., Al-Aly, Z., Alam, K., Alam, N.K.M., Aldhahri, S.F., Alegretti, M.A., Alemu, Z.A., Alexander, L.T., Alhabib, S., Ali, R., Alkerwi, A., Alla, F., Allebeck, P., Al-Raddadi, R., Alsharif, U., Altirkawi, K.A., AlvisGuzman, N., Amare, A.T., Amberbir, A., Amini, H., Ammar, W., Amrock, S.M., Andersen, H.H., Anderson, G.M., Anderson, B.O., Antonio, C.A.T., Aregay, A.F., Ärnlöv, J., Artaman, A., Asayesh, H., Assadi, R., Atique, S., Avokpaho, E.F.G.A., Awasthi, A., Quintanilla, B.P.A., Azzopardi, P., Bacha, U., Badawi, A., Balakrishnan, K., Banerjee, A., Barac, A., Barker-Collo, S.L., Bärnighausen, T., Barregard, L., Barrero, L.H., Basu, A., Bazargan-Hejazi, S., Beghi, E., Bell, B., Bell, M.L., Bennett, D.A., Bensenor, I.M., Benzian, H., Berhane, A., Bernabé, E., Betsu, B.D., Beyene, A.S., Bhala, N., Bhatt, S., Biadgilign, S., Bienhoff, K., Bikbov, B., Biryukov, S., Bisanzio, D., Bjertness, E., Blore, J., Borschmann, R., Boufous, S., Brainin, M., Brazinova, A., Breitborde, N.J.K., Brown, J., Buchbinder, R., Buckle, G.C., Butt, Z.A., Calabria, B., Campos-Nonato, I.R., Campuzano, J.C., Carabin, H., Cárdenas, R., Carpenter, D.O., Carrero, J.J., Castañeda-Orjuela, C.A., Rivas, J.C., CataláLópez, F., Chang, J.-C., Chiang, P.P.-C., Chibueze, C.E., Chisumpa, V.H., Choi, J.-Y.J., Chowdhury, R., Christensen, H., Christopher, D.J., Ciobanu, L.G., Cirillo, M., Coates, M.M., Colquhoun, S.M., Cooper, C., Cortinovis, M., Crump, J.A., Damtew, S.A., Dandona, R., Daoud, F., Dargan, P.I., das Neves, J., Davey, G., Davis, A.C., Leo, D. De, Degenhardt, L., Gobbo, L.C. Del, Dellavalle, R.P., Deribe, K., Deribew, A., Derrett, S., Jarlais, D.C. Des, Dharmaratne, S.D., Dhillon, P.K., Diaz-Torné, C., Ding, E.L., Driscoll, T.R., Duan, L., Dubey, M., Duncan, B.B., Ebrahimi, H., Ellenbogen, R.G., Elyazar, I., Endres, M., Endries, A.Y., Ermakov, S.P., Eshrati, B., Estep, K., Farid, T.A., Farinha, C.S. e S., Faro, A., Farvid, M.S., Farzadfar, F., Feigin, V.L., Felson, D.T., Fereshtehnejad, S.-M., Fernandes, J.G., Fernandes, J.C., Fischer, F., Fitchett, J.R.A., Foreman, K., Fowkes, F.G.R., Fox, J., Franklin, R.C., Friedman, J., Frostad, J., Fürst, T., Futran, N.D., Gabbe, B., Ganguly, P., Gankpé, F.G., Gebre, T., Gebrehiwot, T.T., Gebremedhin, A.T., Geleijnse, J.M., Gessner, B.D., Gibney, K.B., Ginawi, I.A.M., Giref, A.Z., Giroud, M., Gishu, M.D., Giussani, G., Glaser, E., Godwin, W.W., Gomez-Dantes, H., Gona, P., Goodridge, A., Gopalani, S.V., Gotay, C.C., Goto, A., Gouda, H.N., Grainger, R., Greaves, F., Guillemin, F., Guo, Y., Gupta, R., Gupta, R., Gupta, V., Gutiérrez, R.A., Haile, D., Hailu, A.D., Hailu, G.B., Halasa, Y.A., Hamadeh, R.R., Hamidi, S., Hammami, M., Hancock, J., Handal, A.J., Hankey, G.J., Hao, Y., Harb, H.L., Harikrishnan, S., Haro, J.M., Havmoeller, R., Hay, R.J., Heredia-Pi, I.B., Heydarpour, P., Hoek, H.W., Horino, M., Horita, N., Hosgood, H.D., Hoy, D.G., Htet, A.S., Huang, H., Huang, J.J., Huynh, C., Iannarone, M., Iburg, K.M., Innos, K., Inoue, M., Iyer, V.J., Jacobsen, K.H., Jahanmehr, N., Jakovljevic, M.B., Javanbakht, M., Jayaraman, S.P., Jayatilleke, A.U., Jee, S.H., Jeemon, P., Jensen, P.N., Jiang, Y., Jibat, T., Jimenez-Corona, A., Jin, Y., Jonas, J.B., Kabir, Z., Kalkonde, Y., Kamal, R., Kan, H., Karch, A., Karema, C.K., Karimkhani, C., Kasaeian, A., Kaul, A., Kawakami, N., Keiyoro, P.N., Kemp, A.H., Keren, A., Kesavachandran, C.N., Khader, Y.S., Khan, A.R., Khan, E.A., Khang, Y.-H., Khera, S., Khoja, T.A.M., Khubchandani, J., Kieling, C., Kim, P., Kim, C., Kim, D., Kim, Y.J., Kissoon, N., Knibbs, L.D., Knudsen, A.K., Kokubo, Y., Kolte, D., Kopec, J.A., Kosen, S., Kotsakis, G.A., Koul, P.A., Koyanagi, A., Kravchenko, M., Defo, B.K., Bicer, B.K., Kudom, A.A., Kuipers, E.J., Kumar, G.A., Kutz, M., Kwan, G.F., Lal, A., Lalloo, R., Lallukka, T., Lam, H., Lam, J.O., Langan, S.M., Larsson, A., Lavados, P.M., Leasher, J.L., Leigh, J., Leung, R., Levi, M., Li, Y., Li, Y., Liang, J., Liu, S., Liu, Y., Lloyd, B.K., Lo, W.D., Logroscino, G., Looker, K.J., Lotufo, P.A., Lunevicius, R., Lyons, R.A., Mackay, M.T., Magdy, M., Razek, A. El, Mahdavi, M., Majdan, M., Majeed, A., Malekzadeh, R., 
Marcenes, W., Margolis, D.J., Martinez-Raga, J., Masiye, F., Massano, J., McGarvey, S.T., McGrath, J.J., McKee, M., McMahon, B.J., Meaney, P.A., Mehari, A., Mejia-Rodriguez, F., Mekonnen, A.B., Melaku, Y.A., Memiah, P., Memish, Z.A., Mendoza, W., Meretoja, A., Meretoja, T.J., Mhimbira, F.A., Millear, A., Miller, T.R., Mills, E.J., Mirarefin, M., Mitchell, P.B., Mock, C.N., Mohammadi, A., Mohammed, S., Monasta, L., Hernandez, J.C.M., Montico, M., Mooney, M.D., Moradi-Lakeh, M., Morawska, L., Mueller, U.O., Mullany, E., Mumford, J.E., Murdoch, M.E., Nachega, J.B., Nagel, G., Naheed, A., Naldi, L., Nangia, V., Newton, J.N., Ng, M., Ngalesoni, F.N., Nguyen, Q. Le, Nisar, M.I., Pete, P.M.N., Nolla, J.M., Norheim, O.F., Norman, R.E., Norrving, B., Nunes, B.P., Ogbo, F.A., Oh, I.-H., Ohkubo, T., Olivares, P.R., Olusanya, B.O., Olusanya, J.O., Ortiz, A., Osman, M., Ota, E., PA, M., Park, E.-K., Parsaeian, M., de Azeredo Passos, V.M., Caicedo, A.J.P., Patten, S.B., Patton, G.C., Pereira, D.M., Perez-Padilla, R., Perico, N., Pesudovs, K., Petzold, M., Phillips, M.R., Piel, F.B., Pillay, J.D., Pishgar, F., Plass, D., Platts-Mills, J.A., Polinder, S., Pond, C.D., Popova, S., Poulton, R.G., Pourmalek, F., Prabhakaran, D., Prasad, N.M., Qorbani, M., Rabiee, R.H.S., Radfar, A., Rafay, A., Rahimi, K., Rahimi-Movaghar, V., Rahman, M., Rahman, M.H.U., Rahman, S.U., Rai, R.K., Rajsic, S., Ram, U., Rao, P., Refaat, A.H., Reitsma, M.B., Remuzzi, G., Resnikoff, S., Reynolds, A., Ribeiro, A.L., Blancas, M.J.R., Roba, H.S., Rojas-Rueda, D., Ronfani, L., Roshandel, G., Roth, G.A., Rothenbacher, D., Roy, A., Sagar, R., Sahathevan, R., Sanabria, J.R., Sanchez-Niño, M.D., Santos, I.S., Santos, J.V., Sarmiento-Suarez, R., Sartorius, B., Satpathy, M., Savic, M., Sawhney, M., Schaub, M.P., Schmidt, M.I., Schneider, I.J.C., Schöttker, B., Schwebel, D.C., Scott, J.G., Seedat, S., Sepanlou, S.G., Servan-Mori, E.E., Shackelford, K.A., Shaheen, A., Shaikh, M.A., Sharma, R., Sharma, U., Shen, J., Shepard, D.S., Sheth, K.N., Shibuya, K., Shin, M.-J., Shiri, R., Shiue, I., Shrime, M.G., Sigfusdottir, I.D., Silva, D.A.S., Silveira, D.G.A., Singh, A., Singh, J.A., Singh, O.P., Singh, P.K., Sivonda, A., Skirbekk, V., Skogen, J.C., Sligar, A., Sliwa, K., Soljak, M., Søreide, K., Sorensen, R.J.D., Soriano, J.B., Sposato, L.A., Sreeramareddy, C.T., Stathopoulou, V., Steel, N., Stein, D.J., Steiner, T.J., Steinke, S., Stovner, L., Stroumpoulis, K., Sunguya, B.F., Sur, P., Swaminathan, S., Sykes, B.L., Szoeke, C.E.I., Tabarés-Seisdedos, R., Takala, J.S., Tandon, N., Tanne, D., Tavakkoli, M., Taye, B., Taylor, H.R., Ao, B.J. Te, Tedla, B.A., Terkawi, A.S., Thomson, A.J., ThorneLyman, A.L., Thrift, A.G., Thurston, G.D., Tobe-Gai, R., Tonelli, M., Topor-Madry, R., Topouzis, F., Tran, B.X., Truelsen, T., Dimbuene, Z.T., Tsilimbaris, M., Tura, A.K., Tuzcu, E.M., Tyrovolas, S., Ukwaja, K.N., Undurraga, E.A., Uneke, C.J., Uthman, O.A., van Gool, C.H., Varakin, Y.Y., Vasankari, T., Venketasubramanian, N., Verma, R.K., Violante, F.S., Vladimirov, S.K., Vlassov, V.V., Vollset, S.E., Wagner, G.R., Waller, S.G., Wang, L., Watkins, D.A., Weichenthal, S., Weiderpass, E., Weintraub, R.G., Werdecker, A., Westerman, R., White, R.A., Williams, H.C., Wiysonge, C.S., Wolfe, C.D.A., Won, S., Woodbrook, R., Wubshet, M., Xavier, D., Xu, G., Yadav, A.K., Yan, L.L., Yano, Y., Yaseri, M., Ye, P., Yebyo, H.G., Yip, P., Yonemoto, N., Yoon, S.-J., Younis, M.Z., Yu, C., Zaidi, Z., Zaki, M.E.S., Zeeb, H., Zhou, M., Zodpey, S., Zuhlke, L.J., Murray, C.J.L., 2016. Global, regional, and national incidence, prevalence, and years lived with disability for 310 diseases and injuries, 1990-2015: a systematic analysis for the Global Burden of Disease Study 2015. Lancet 388, 1545-1602.

Wallach, C.J., Sobajima, S., Watanabe, Y., Kim, J.S., Georgescu, H.I., Robbins, P., Gilbertson, L.G., Kang, J.D., 2003. Gene transfer of the catabolic inhibitor TIMP-1 increases measured proteoglycans in cells from degenerated human intervertebral discs. Spine (Phila. Pa. 1976). 
Walter, B. a, Purmessur, D., Likhitpanichkul, M., Weinberg, A., Cho, S.K., Qureshi, S. a., Hecht, A.C., Iatridis, J.C., 2015. Inflammatory Kinetics and Efficacy of Anti-inflammatory Treatments on Human Nucleus Pulposus Cells. Spine (Phila. Pa. 1976). 40, 1.

Wan, S., Borland, S., Richardson, S.M., Merry, C.L.R., Saiani, A., Gough, J.E., 2016. Selfassembling peptide hydrogel for intervertebral disc tissue engineering. Acta Biomater. 46, $29-40$.

Wang, S., Chang, Q., Lu, J., Wang, C., 2015. Growth factors and platelet-rich plasma: promising biological strategies for early intervertebral disc degeneration. Int. Orthop. 39, 927-934.

Wang, W.-J., Yu, X.-H., Wang, C., Yang, W., He, W.-S., Zhang, S.-J., Yan, Y.-G., Zhang, J., 2015. MMPs and ADAMTSs in intervertebral disc degeneration. Clin. Chim. Acta. 448.

Wei, X.W., Gong, C.Y., Gou, M.L., Fu, S.Z., Guo, Q.F., Shi, S., Luo, F., Guo, G., Qiu, L.Y., Qian, Z.Y., 2009. Biodegradable poly(e-caprolactone)-poly(ethylene glycol) copolymers as drug delivery system. Int. J. Pharm. 381, 1-18.

Wenk, E., Meinel, A.J., Wildy, S., Merkle, H.P., Meinel, L., 2009. Microporous silk fibroin scaffolds embedding PLGA microparticles for controlled growth factor delivery in tissue engineering. Biomaterials 30, 2571-2581.

Whatley, B.R., Wen, X., 2012. Intervertebral disc (IVD) : Structure, degeneration, repair and regeneration. Mater. Sci. Eng. C 32, 61-77.

Wilczewska, A.Z., Niemirowicz, K., Markiewicz, K.H., Car, H., 2012. Nanoparticles as drug delivery systems. Pharmacol Rep 64, 1020-1037.

Willems, N., Yang, H.-Y., Langelaan, M.L.P., Tellegen, A.R., Grinwis, G.C.M., Kranenburg, H.J.C., Riemers, F.M., Plomp, S.G.M., Craenmehr, E.G.M., Dhert, W.J.A., Papen-Botterhuis, N.E., Meij, B.P., Creemers, L.B., Tryfonidou, M.A., 2015. Biocompatibility and intradiscal application of a thermoreversible celecoxib-loaded poly-N-isopropylacrylamide $\mathrm{MgFe}$ layered double hydroxide hydrogel in a canine model. Arthritis Res. Ther. 17, 214.

Wismer, N., Grad, S., Fortunato, G., Ferguson, S.J., Alini, M., Eglin, D., 2014. Biodegradable electrospun scaffolds for annulus fibrosus tissue engineering: effect of scaffold structure and composition on annulus fibrosus cells in vitro. Tissue Eng. Part A 20, 672-82.

Wu, J., Guan, T., Zheng, S., Grosjean, F., Liu, W., Xiong, H., Gordon, R., Vlassara, H., Striker, G.E., Zheng, F., 2011. Inhibition of inflammation by pentosan polysulfate impedes the development and progression of severe diabetic nephropathy in aging C57B6 mice. Lab. Investig. 91, 1459-1471.

Yan, J., Yang, S., Sun, H., Guo, D., Wu, B., Ji, F., Zhou, D., 2013. Effects of releasing recombinant human growth and differentiation factor-5 from poly(lactic-co-glycolic acid) microspheres for repair of the rat degenerated intervertebral disc. J. Biomater. Appl. 29, $72-$ 80.

Yang, H., Gao, F., Li, X., Wang, J., Liu, H., Zheng, Z., 2015. TGF- $\beta 1$ antagonizes TNF- $\alpha$ induced up-regulation of matrix metalloproteinase 3 in nucleus pulposus cells: role of the ERK1/2 pathway. Connect. Tissue Res. 8207, 1-8.

Yang, Y., Yu, C., 2016. Advances in silica based nanoparticles for targeted cancer therapy. Nanomedicine 12, 317-32. 
Zeng, Y., Kurokawa, Y., Win-Shwe, T.-T., Zeng, Q., Hirano, S., Zhang, Z., Sone, H., 2016. Effects of PAMAM dendrimers with various surface functional groups and multiple generations on cytotoxicity and neuronal differentiation using human neural progenitor cells. J. Toxicol. Sci. 41, 351-70.

Zhang, H., Zhang, L., Chen, L., Li, W., Li, F., Chen, Q., 2014. Stromal cell-derived factor-1 and its receptor CXCR4 are upregulated expression in degenerated intervertebral discs. Int. J. Med. Sci. 11, 240-245.

Zhao, Y., Fan, X., Liu, D., Wang, Z., 2011. PEGylated thermo-sensitive poly(amidoamine) dendritic drug delivery systems. Int. J. Pharm. 409, 229-236.

Zhongyi, S., Sai, Z., Chao, L., Jiwei, T., 2015. Effects of nuclear factor kappa B signaling pathway in human intervertebral disc degeneration. Spine (Phila. Pa. 1976). 40, 224-32.

Zhou, X., Chen, L., Grad, S., Alini, M., Pan, H., Yang, D., Zhen, W., Li, Z., Huang, S., Peng, S., 2017. The roles and perspectives of microRNAs as biomarkers for intervertebral disc degeneration. J. Tissue Eng. Regen. Med. Ahead of print.

Zhou, Z., Gao, M., Wei, F., Liang, J., Deng, W., Dai, X., Zhou, G., Zou, X., 2014. Shock absorbing function study on denucleated intervertebral disc with or without hydrogel injection through static and dynamic biomechanical tests in vitro. Biomed Res. Int. 2014, 461724. 

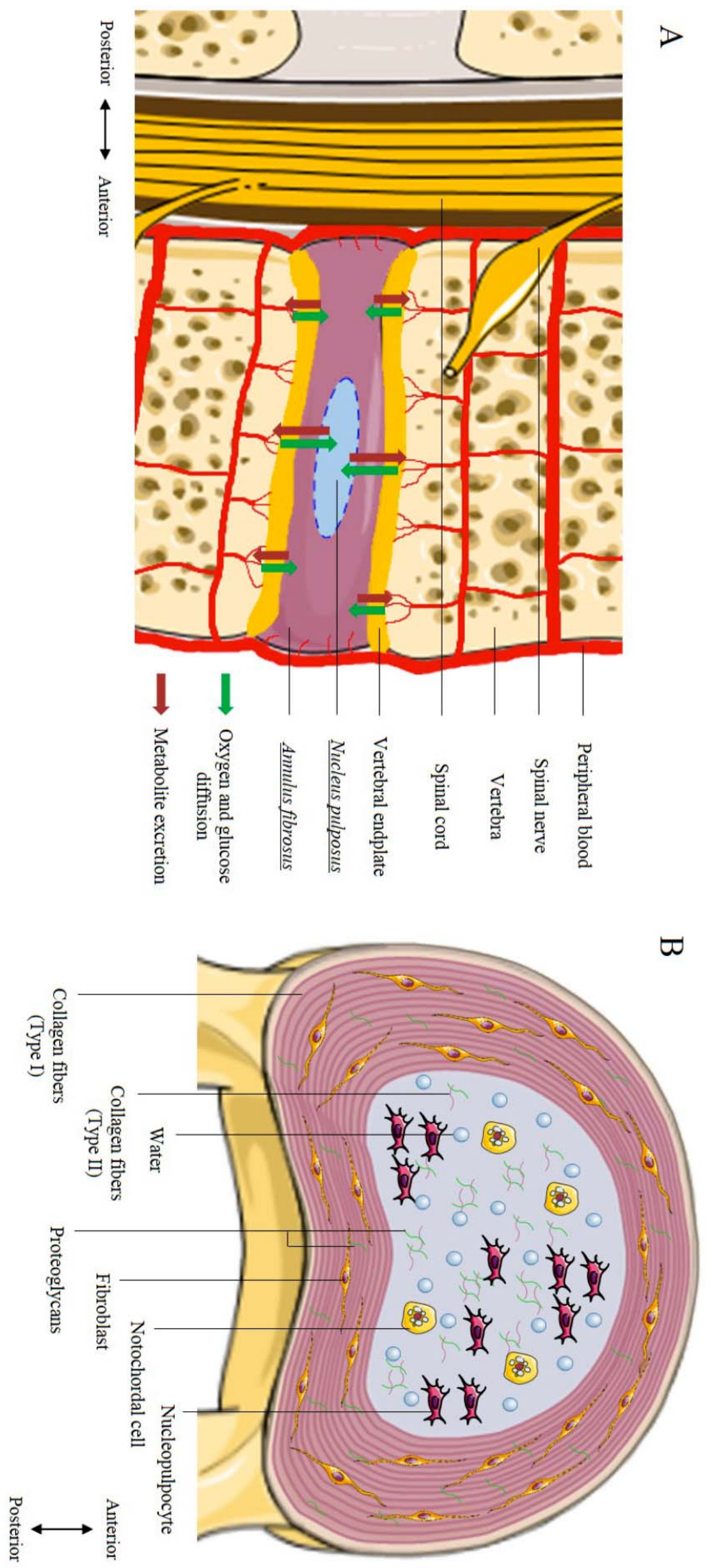


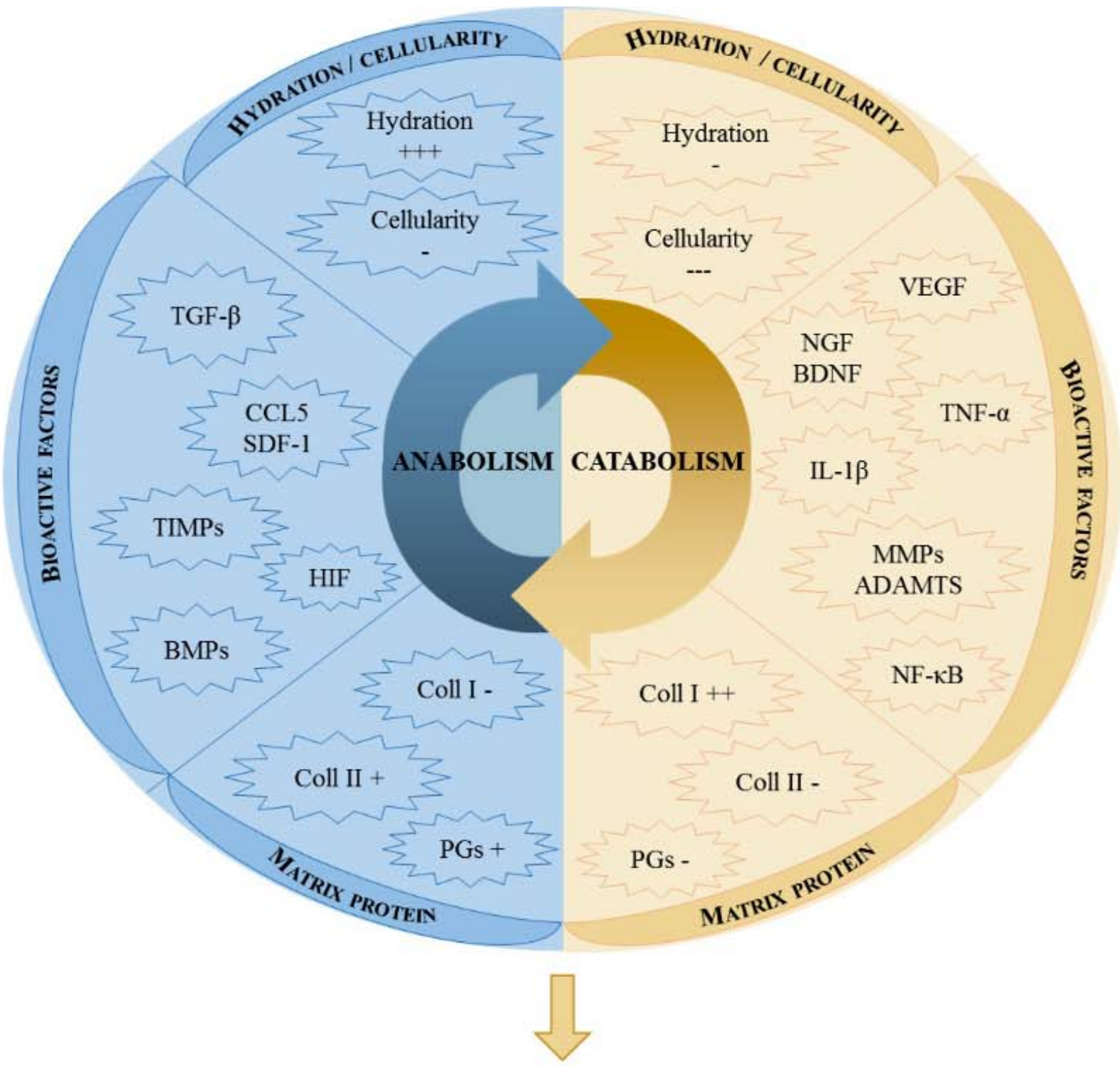

$\downarrow$ Anabolism + Catabolism $\uparrow$

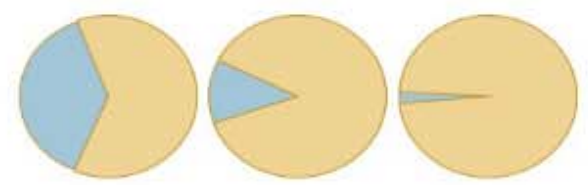

$\sqrt{5}$

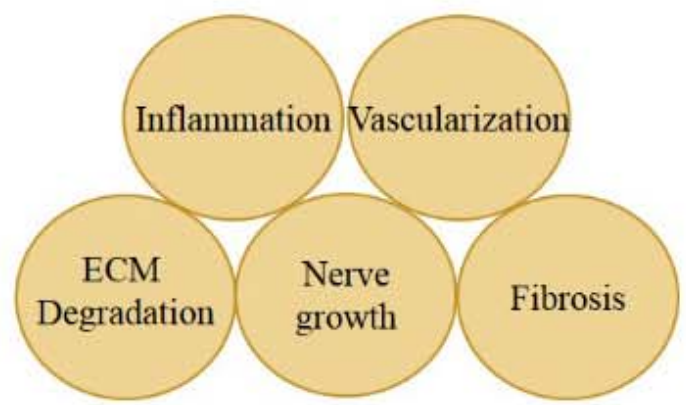

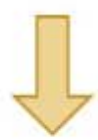

DISC DEGENERATIVE

DISEASE 


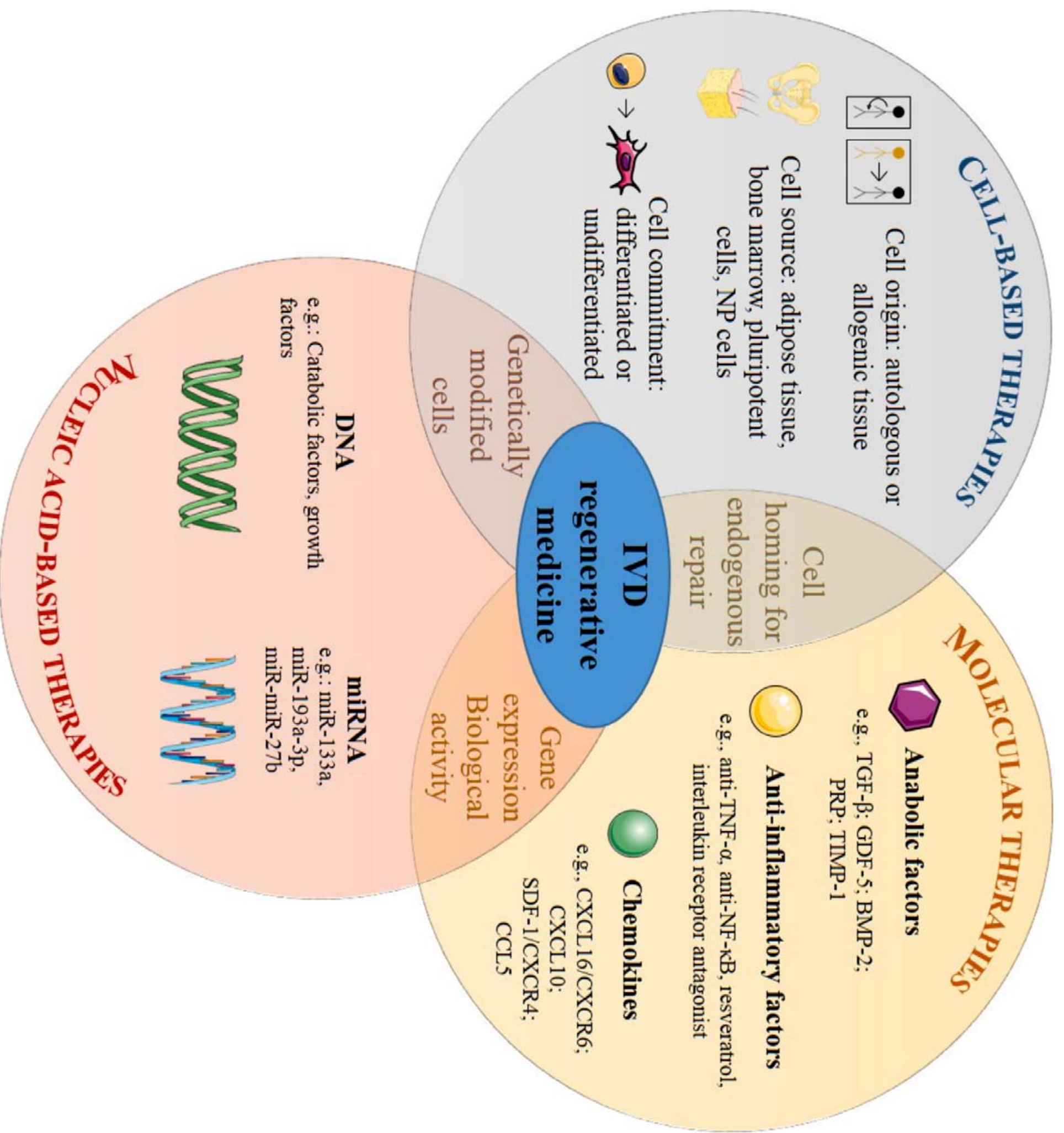




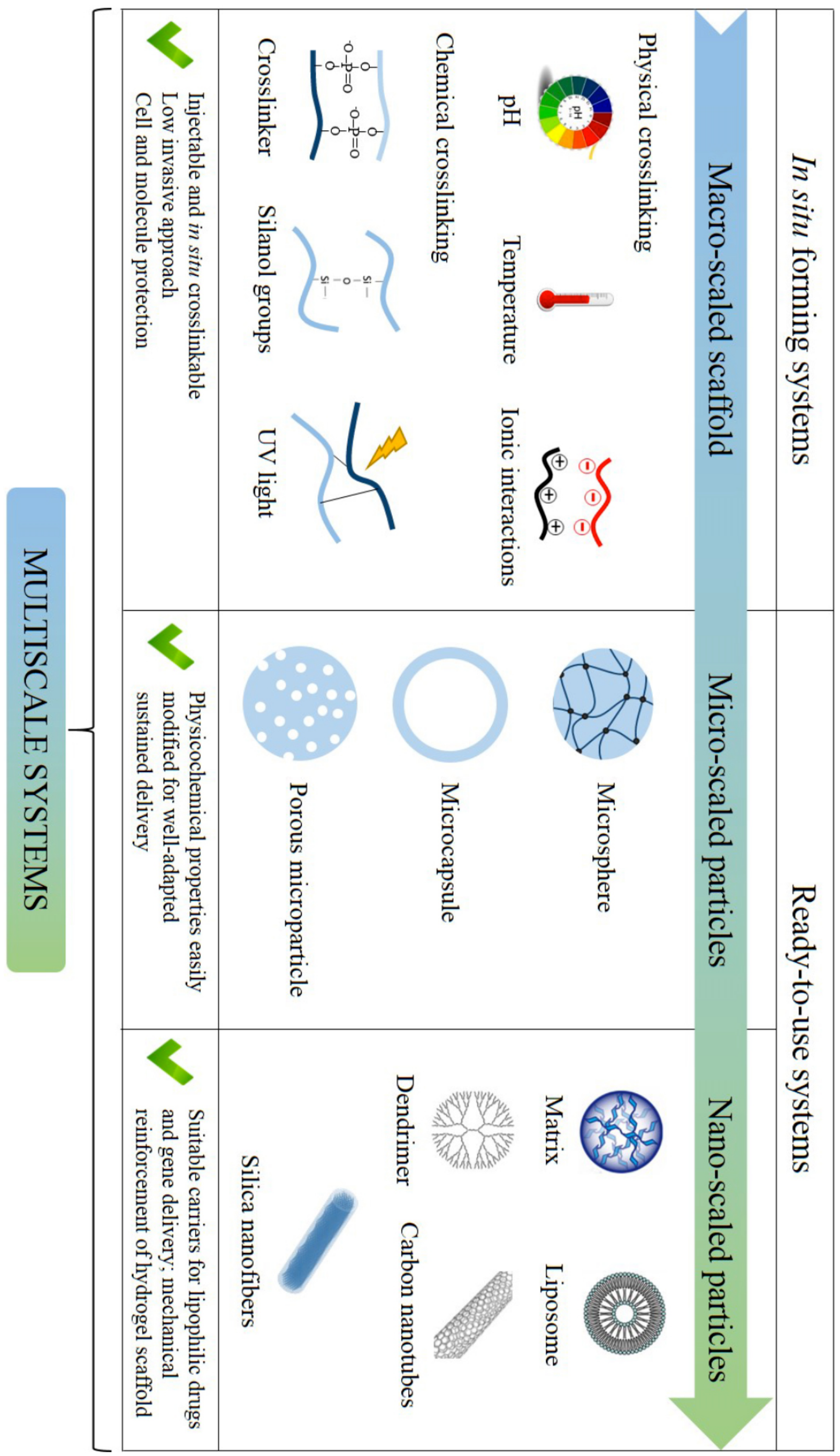




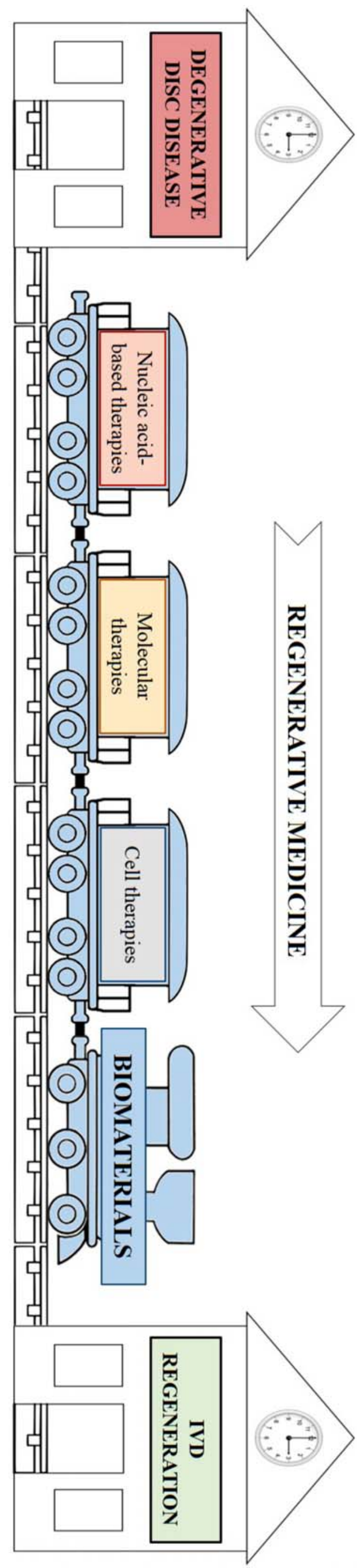

